Su, M., Young, B. and Gardner, L. (2014) "Deformation-based design of aluminum alloy beams" Engineering Structures, 80: 339-349.

\title{
Deformation-based design of aluminium alloy beams
}

\author{
Mei-Ni Su ${ }^{1}$, Ben Young ${ }^{2}$ and Leroy Gardner ${ }^{3}$
}

\begin{abstract}
Two series of simply supported bending tests on aluminium alloy square and rectangular hollow sections have been performed. The test program comprised 14 three-point bending tests and 15 four-point bending tests. The test specimens were fabricated by extrusion from grades 6061-T6 and 6063-T5 heat-treated aluminium alloys, with width-to-thickness ratios ranging from 2.8 to 20.5. Measured geometric and material properties, together with the full load-deflection histories from the test specimens, were reported. Observed failure modes included local buckling, material yielding and tensile fracture. Further experimental data were gathered from the literature. Finite element (FE) models were developed and validated against the test results, and then used to perform parametric studies, in which a total of 132 numerical results were generated. The experimental and numerical results were used to evaluate the bending resistance provisions of the American [1], Australian/New Zealand [2] and European [3] Specifications, as well as the continuous strength method (CSM). The moment capacities predicted by the three design specifications were found to be generally conservative, while the CSM provided more accurate and more consistent predictions due to the recognition and systematic exploitation of strain hardening.
\end{abstract}

KEY WORDS: Aluminium alloys; Bending moment capacities; Continuous strength method; Experimental investigation; Flexure; I-sections; Numerical analysis; Simply supported beams; Square and rectangular hollow sections; Structural design. 
${ }^{1} \mathrm{PhD}$ Candidate, Dept. of Civil Engineering, The Univ. of Hong Kong, Pokfulam, Hong Kong / Dept. of Civil and Environmental Engineering, Imperial College London, London SW7 2AZ, UK

${ }_{2}^{2}$ Professor, Dept. of Civil Engineering, The Univ. of Hong Kong, Pokfulam, Hong Kong. E-mail: young@hku.hk

${ }^{3}$ Professor, Dept. of Civil and Environmental Engineering, Imperial College London, London SW7 2AZ, UK. Email: leroy.gardner@imperial.ac.uk

\section{Introduction}

Aluminium alloys are gaining increasing usage in the construction industry, offering high strength-to-weight ratios, good durability and ease of fabrication. A wide variety of cross-section types are available, enabling aluminium alloys to be used efficiently under a broad range of loading conditions. The behaviour of design of aluminium alloy cross-sections in flexure is the subject of the present study.

The earliest documented structural tests on aluminium alloy members subjected to bending were conducted by Dumont and Hill [4]. Since then, both experimental and numerical studies have been carried out by numerous researchers, seeking to improve the design provisions for aluminium alloy beams. For instance, Lai and Nethercot [5] developed finite element (FE) models, which incorporated heat-affected zones to investigate their influence on flexural capacity. Moen et al. [6, 7], De Matteis et al. [8, 9] and Manganiello et al. [10] conducted a number of experimental and numerical investigations into the strength and rotation capacity of aluminium alloy beams subjected to a moment gradient. Eberwien and Valtinat [11] proposed a method to obtain the moment-curvature response of symmetrical aluminium cross-sections, while recently, the direct strength method (DSM), initially developed by Schafer and Peköz [12] for the design of cold-formed steel structural members, was extended to aluminium alloy thin-walled sections, and verified against a series of beam tests conducted by Zhu and Young [13]. 
The post-yield material properties of aluminium alloys - strain hardening and ductility - have been found to have a strong influence on the flexural behaviour of aluminium alloy beams [6, 7 , 14]. With an emphasis on these two factors, Kim and Peköz [15] conducted tests and developed numerical models of aluminium alloy stocky section beams to determine the ultimate inelastic bending capacities, where it was found that the ultimate material strength could be achieved. Recently, a deformation-based design approach, the continuous strength method (CSM), was proposed for non-linear metallic structural members [16-20]. The CSM involves determining a limiting strain for the cross-section which is used in conjunction with a strain hardening material model to determine load-carrying capacities.

There are a number of international aluminium alloy design specifications. The most widely used are the Aluminum Design Manual [1], the Australian/New Zealand Standard [2] and Eurocode 9 [3]. The width-to-thickness ratio and the yield stress are recognized as the governing design parameters in the design of cross-sections in these specifications. In the case of flexural members, the design strengths predicted by these specifications are generally overly conservative $[6,13,15$ and 21], especially for stocky (non-slender) sections. This is recognised in Annex F of EC9 [3], where an alternative design method accounting for strain hardening is provided, and this more favourable approach is employed herein for all comparisons made with EC9.

The majority of available beam test results from the literature relate to experiments conducted on specimens of relatively slender proportions. Hence, the assessment of design specifications for stocky cross-sections is relatively limited. This paper firstly presents three-point and four-point bending tests on aluminium alloy tubular sections, the results of which are subsequently compared. Secondly, numerical models of both configurations are developed and validated against the experimental data, after which a parametric study is conducted to generate 132 
additional numerical results. Finally, the test and numerical results generated in the present study, together with those gathered from previous tests conducted by other researchers, are compared with the design strengths predicted by the American [1], Australian/New Zealand [2] and European [3] specifications as well as the CSM.

\section{Experimental investigation}

An experimental program comprising three-point and four-point bending tests was conducted on aluminium alloy square and rectangular hollow sections (SHS/RHS). The test specimens were manufactured by extrusion from grades 6061-T6 and 6063-T5 heat-treated aluminium alloys. There were 29 flexural specimens, defined using the symbols illustrated in Figure 1. The crosssectional dimensions and tensile material properties shown in Tables 1 and 2 are the average measured values for each test specimen. The symbols presented in Tables 1 and 2 are defined as follows: $L$ is the beam length, $E$ is the Young's modulus, $f_{y}$ is the $0.2 \%$ proof stress, which is conventionally used as the yield stress, $f_{u}$ is the ultimate tensile stress and $n$ is the exponent of the Ramberg-Osgood expression. The measured material properties of each specimen were determined by means of longitudinal tensile coupon tests and Webster hardness measurements. Coupon tests conformed to the Australian standard AS 1391 [22] and the ASTM standard [23]. Webster hardness measurements were conducted according to the Standard Test Method for Indentation Hardness of Aluminium Alloys by Means of a Webster Hardness Gage [24]. The average measured local imperfection amplitude of the test specimens was $0.2 \mathrm{~mm}$.

The specimens were labelled according to the type of material, cross-sectional dimensions and test configuration. For example, the label "H70×55×4.2B3-R" defines an RHS specimen of high "H” strength aluminium alloy 6061-T6, with nominal cross-sectional dimensions of width (70 $\mathrm{mm}) \times$ height $(55 \mathrm{~mm}) \times$ thickness $(4.2 \mathrm{~mm})$. If the label starts with "N", it means the specimen is 
of normal strength aluminium alloy 6063-T5. The symbol "B3" following the dimensions refers to the three-point loading configuration, whereas "B4" signifies the four-point loading configuration. If a test is repeated, a letter " $\mathrm{R}$ " is included in the label. The arrangement of the cross-sectional dimensions also refers to the bending axis. In this case, the specimen H70 $\times 55 \times 4.2 \mathrm{~B} 3-\mathrm{R}$ was bent about the minor axis, while the specimen $\mathrm{H} 55 \times 70 \times 4.2 \mathrm{~B} 3$ was bent about the major axis.

The bending tests were conducted to assess the flexural resistance and rotation capacity of aluminium alloy beams, as well as the significance of strain hardening. Stiffening steel plates of $100 \mathrm{~mm}$ width and $10 \mathrm{~mm}$ thickness, as well as wooden blocks, were employed at the loading points and the supports to prevent web crippling due to load concentration. Furthermore, steel bearing plates were placed between the specimens and rollers/half rounds for the purpose of spreading the concentrated loads. A servo-controlled hydraulic testing machine was used to apply compressive force by displacement control to the specimens at a constant rate of $0.8 \mathrm{~mm} / \mathrm{min}$. The applied loads, as well as the readings from the LVDTs and strain gauges, were recorded by a data logger at one second intervals during the tests. Hinges and pins were simulated by half rounds and rollers, respectively. The distance between the loading point and the supports was $300 \mathrm{~mm}$. In the three-point bending tests, the simply supported specimens were loaded at the mid-span, as shown in Figures 2 and 3. One $100 \mathrm{~mm}$ LVDT was used to measure the vertical deflection at mid-span. Two $25 \mathrm{~mm}$ LVDTs were placed at each end of the specimens to measure the end rotation. For the relatively slender sections $(\mathrm{H} 70 \times 55 \times 4.2 \mathrm{~B} 3$, $\mathrm{H} 55 \times 70 \times 4.2 \mathrm{~B} 3$ and $\mathrm{H} 64 \times 64 \times 3.0 \mathrm{~B} 3)$, three strain gauges were adhered to the compression flange at a distance of $5 \mathrm{~mm}$ from the loading point, with two gauges near the flange-web junctions and one in the middle of the flange, to monitor possible local buckling. The moment-end rotation curves from the three-point bending tests are plotted in Figure 4. In the four-point bending tests, the simply supported specimens were loaded 
symmetrically at two points through a spreader beam, as shown in Figures 5 and 6. One $100 \mathrm{~mm}$ LVDT and two $50 \mathrm{~mm}$ LVDTs were used to measure the vertical deflection at mid-span and at the loading points, respectively, in order to obtain the mid-span deflection and curvature in the constant moment region. Two 25 mm LVDTs were placed at each end of the beams to measure the end rotation. As for the three-point bending tests, three strain gauges were affixed at mid-span on the compression flange for the relatively slender sections $(\mathrm{H} 70 \times 55 \times 4.2 \mathrm{~B} 4, \mathrm{H} 55 \times 70 \times 4.2 \mathrm{~B} 4$ and H64×64×3.0B4) to monitor local buckling. The moment-curvature graphs from the four-point bending tests are presented in Figure 7.

The specimens generally failed by spread of plasticity and inelastic local buckling, except for beams $\mathrm{H} 50 \times 95 \times 10.5 \mathrm{~B} 3$ and $\mathrm{H} 70 \times 120 \times 10.5 \mathrm{~B} 3$ which failed by tensile material fracture at midspan. A distinct sound was heard when the material split on the tension flange at failure, as seen in Figure 8. The material fracture failure mode arose in two specimens $(\mathrm{H} 50 \times 95 \times 10.5 \mathrm{~B} 3$ and H70 $\times 120 \times 10.5 B 3$ ), both of which were of very stocky proportions (such that local buckling was precluded) and had reached the plastic moment prior to fracture. It should be noted that significant visual local buckling was not observed in the beams. A comparison between the test results obtained in the three-point and four-point bending configurations is given in Table 3.

Previous studies conducted by other researcher also provide relevant experimental results, including those obtained from three-point bending tests [6] and four-point bending tests [5, 13 and 19], all of which are included in Tables 1 and 2. The data gathered from the literature and the newly generated results from the present study are both used to evaluate the design provisions for aluminium alloy elements in bending given in the three considered specifications and the continuous strength method. The results are summarised in Tables 4 and 5, and will be discussed further in Section 5. 


\section{Numerical study}

Numerical analyses were performed in parallel with the experimental studies. The finite element (FE) package ABAQUS version 6.10 [25] was employed to simulate the bending experiments and to conduct parametric investigations. In the parametric study, the influence of two key parameters of the aluminium alloy beams, namely the cross-sectional slenderness $\bar{\lambda}_{p}$ and the width-to-height ratio $b / h$, was examined.

\subsection{Model validation}

The reduced integration 4-noded doubly curved general-purpose shell element S4R was employed in all FE models, with a chosen mesh size of $10 \mathrm{~mm} \times 10 \mathrm{~mm}$. Bearing plates were modelled using $10 \mathrm{~mm}$ thick solid elements that were free to rotate in-plane. Hard contact in the normal direction and friction penalty contact (with the friction coefficient $=0.1$ ) in the tangential direction were adopted between the solid plate (master surface) and the beam surface (slave surface). It should be noted that, as in the tests, web-crippling was not observed in the numerical models. Simple support conditions were simulated by restraining the relevant degrees of freedom at mid-span and at the ends of the beams. The true material stress-strain relationships were derived from the engineering stress-strain curves obtained from the tensile coupon tests (see Figure 9), and input into ABAQUS. The beams were restrained longitudinally at the mid-span only. Residual stresses were not measured in the experimental work, but have been found previously to have only a very small effect on the load-bearing capacity of aluminium alloy members [26]. Displacement-controlled non-linear analyses were carried out employing the Riks method. 
Initial local geometric imperfections were included in the numerical models. The imperfections were incorporated in the form of the lowest appropriate (i.e. a regular pattern) elastic buckling mode shape as obtained from linear eigenvalue buckling analyses, as shown in Figure 10. The initial geometric imperfection amplitude was taken as $0.2 \mathrm{~mm}$, which represented the average local imperfection amplitudes measured on the test specimens.

The experimental and numerical results are compared in Table 6, and may be seen to be in good overall agreement, indicating that the model was capable of replicating the experimentally observed structural response of the specimens. In general, the initial stiffness, failure modes (Figures 11-12) and the general shape of the moment-rotation curves of the FE models followed those obtained from the experiments closely. Two typical load-displacement curves (for specimen H120×120×9.0B3) obtained from the experiments and FE models are compared in Figure 13 .

\subsection{Parametric study}

Having validated the numerical model against the experimental results, it was used to carry out an extensive parametric study to assess the bending behaviour of aluminium alloy beams over a wider range of cross-section slendernesses. Both major and minor axis bending was modelled. Local imperfections were assumed to be in the pattern of the lowest regular elastic buckling mode shape with an amplitude of $0.2 \mathrm{~mm}$, as measured in the experimental program. The material properties of a typical high strength aluminium alloy specimen $\mathrm{H} 64 \times 64 \times 3.0 \mathrm{~B} 3$ and a typical normal strength aluminium alloy specimen + N95 $\times 50 \times 10.5 B 5 I I I$ (a specimen not reported in this paper with $f_{y}=109.5 \mathrm{MPa}$ and $f_{u}=177.4 \mathrm{MPa}$ ) were employed in the models to represent high strength and normal strength aluminium alloys, respectively. A wide range of both $b / h$ ratios $(0.29$

- 3.35) and $b / t$ ratios (4.25 - 55.14) were considered in the parametric study. Outer section 
dimensions and thickness up to $180 \mathrm{~mm}$ and $12 \mathrm{~mm}$, respectively, were modelled. The distance between supports and loading points varied from $400 \mathrm{~mm}$ to $900 \mathrm{~mm}$. The parametric study generated a total of 132 numerical results, with half in three-point bending and half in four-point bending. The results are compared with a series of design methods in Section 5 of this paper.

\section{Comparison between three-point and four-point bending tests}

Each cross-section in the present study was tested in two loading configurations - three-point bending and four-point bending. In the former case, the members experience a moment gradient with coexistent shear while in the latter case, the members are subjected to a central region of constant moment and zero shear. Typical failed specimens from three-point and four-point bending tests are presented in Figures 11 and 12, respectively. Test moment resistances and rotation capacities, as well as the comparisons between the results obtained for the two loading configurations, are shown in Table 3. Note that an LVDT error occurred in the H120×120×9.0B4 test, which meant that end rotation of this specimen could not be obtained.

It should be noted that the definition of the rotation capacity $R$ related to rotation $\theta_{\text {rot }}$ at the theoretical plastic hinge location for the three-point bending tests (Equation 1) or to constant curvature $\kappa_{\text {rot }}$ developed in the uniform moment region for the four-point bending tests (Equation 2).

$$
\begin{aligned}
& R=\frac{\theta_{r o t}}{\theta_{p l}}-1 \\
& R=\frac{\kappa_{r o t}}{\kappa_{p l}}-1
\end{aligned}
$$


Where $\theta_{p l}$ and $\kappa_{p l}$ are the elastic rotation and curvature corresponding to the plastic moment $M_{p l}=$ $W_{p l f}$ and $\theta_{\text {rot }}$ and $\kappa_{\text {rot }}$ are the rotation and curvature at the point where the moment resistance drops back below $M_{p l}$. The definitions of rotation capacity based on the moment-rotation and the moment-curvature relationships have been explained and employed by Chan and Gardner [27].

It can be seen from Table 3 that the ultimate moment capacities obtained from the three-point bending tests $M_{\text {exp }}(\mathrm{B} 3)$ are consistently higher than those obtained from the four-point bending tests $M_{\text {exp }}(\mathrm{B} 4)$. For the normal strength aluminium (6063-T5) specimens, $M_{\text {exp }}(\mathrm{B} 3) / M_{\text {exp }}(\mathrm{B} 4)$ ranged between 1.12 and 1.41, while for the high strength (6061-T6) material, this ratio varied between 1.01 and 1.20. The presented comparative results obtained in this section coincide with the findings of others [27-31]. This behaviour was explained by the fact that local buckling is delayed in the presence of a moment gradient due to the restraint that the most heavily loaded cross-section experiences from the adjacent material which is at a lower stress level. Meanwhile, similar conclusions are also reached for rotational capacities by Theofanous et al. [28], who found that both the ultimate moment capacity and rotation capacity are improved in the presence of a moment gradient, as compared to uniform bending. However, most of the test moments in this study did not drop back below $M_{p l}$ due to large deformations and premature fracture, which prevents meaningful comparisons of rotation capacity.

\section{COMPARISON OF TEST RESULTS WITH DESIGN STRENGTHS}

In this section, the ultimate bending capacities obtained from the testing $\left(M_{\text {exp }}\right)$ and numerical modelling $\left(M_{F E}\right)$ carried out in the present study, as well as from existing experiments collected from the literature are compared with the calculated elastic $\left(M_{e l}\right)$ and plastic $\left(M_{p l}\right)$ moments, and the nominal flexural design strengths predicted by the Aluminum Design Manual [1] $\left(M_{A A}\right)$, the 
Australian/New Zealand Standard [2] ( $\left.M_{A S / N Z S}\right)$, Eurocode 9 [3] $\left(M_{E C 9}\right)$ and the continuous strength method $\left(M_{c s m}\right)$ for aluminium structures -see Tables 4, 5 and 7 as well as Figures 14-15. The comparisons were performed using the measured material properties and geometries, with all safety factors set equal to unity. The AA [1] provides design rules for aluminium alloy simply supported beams, in which the nominal weighted average design moment is defined as the sum of elastic modulus of each element multiplied by its individual flexural stress, as indicated in Clause F8.3, Part I of the Aluminum Design Manual [1]. The design rules in the AS/NZS provisions are similar to the AA, except using the weighted average compressive stress for the gross section, i.e. the average value of flexural stress in terms of each compressive element's area. In EC9, resistance is defined as the yield stress multiplied by the plastic modulus $W_{p l}$ for Class 1 and 2 sections, by the elastic modulus $W_{e l}$ for Class 3 sections and by the elastic modulus of an effective section $W_{\text {eff }}$ for slender Class 4 cross-sections. EC9 also provides an alternative design method in Annex F to enable higher capacities to be determined for Class 1 sections by taking account of strain hardening. All comparisons made herein with EC9 use the more favourable Annex F approach.

The continuous strength method (CSM) is a deformation based design framework that allows for the beneficial influence of strain hardening for all non-slender cross-sections [16-20]. A base curve defining a continuous relationship between local slenderness and cross-section deformation capacity [19] together with a strain hardening material model [20] are the two main features of the CSM. The relationships between moment capacity and cross-section slenderness for the four considered design methods (AA, AS/NZS, EC9 and CSM) are illustrated in Figure 16.

The CSM base curve, given by Equation 2, where $\varepsilon_{c s m}$ is the limiting strain for the cross-section, $\varepsilon_{y}=f_{y} / E$ is the yield strain and $\bar{\lambda}_{p}$ is the cross-section slenderness, has already been shown to 
provide an accurate prediction of deformation capacity for carbon steel and stainless steel crosssections in compression and bending [19], as well as aluminium alloy cross-sections in compression [20]. In Figure 17, the deformation capacities obtained from the bending tests and numerical models generated herein are plotted against cross-section slenderness, alongside the CSM base curve. The deformation capacities were derived from the four-point bending tests and models following the procedure described in [19]. For comparison, deformation capacity data derived from experiments on aluminium alloy cross-sections in compression [20] are also shown in Figure 17. The base curve may be seen to provide a good representation of both the compression and bending data, indicating its suitability for the prediction of the deformation capacity of aluminium alloy cross-sections.

$\frac{\varepsilon_{C S m}}{\varepsilon_{y}}=\frac{0.25}{\bar{\lambda}_{p}^{3.6}}$ but $\frac{\varepsilon_{C S m}}{\varepsilon_{y}} \leq$ lesser $\left(15, \frac{0.5 \varepsilon_{u}}{\varepsilon_{y}}\right) \quad$ for $\bar{\lambda}_{p} \leq 0.68$

Cross-section slenderness $\bar{\lambda}_{p}$ is defined as:

$\bar{\lambda}_{p}=\sqrt{f_{y} / \sigma_{c r}}$

where $\sigma_{c r}$ is the elastic buckling stress of the cross-section, which may be determined numerically using programs such as CUFSM [32] or using simplified analytical expressions [33]. Alternatively, $\bar{\lambda}_{p}$ may be determined on an element by element basis, by taking the cross-section slenderness as that of its most slender constituent plate.

Using the base curve (Equation 2) to determine the level of strain that a cross-section can carry $\varepsilon_{c s m}$, cross-section resistance may then be derived by means of a suitable material $\sigma-\varepsilon$ model. The 
CSM employs a bi-linear (elastic, linear hardening) material model, as shown in Figure 18, where the slope of the strain hardening region $E_{\text {sh }}$ is given by:

$$
E_{s h}=\frac{f_{u}-f_{y}}{0.5 \varepsilon_{u}-\varepsilon_{y}}
$$

where $\varepsilon_{u}$ is the strain at the material ultimate tensile stress, which may be taken as [20]:

$$
\varepsilon_{u}=0.13\left(1-f_{y} / f_{u}\right)+0.059
$$

Having determined the strain hardening modulus $E_{\text {sh }}$, cross-section bending resistance $M_{c s m}$ may subsequently be determined from Equation 6, which was derived from simple mechanism in [17].

$$
M_{C S m}=W_{p l} f_{y}\left[1+\frac{E_{S h}}{E} \frac{W_{e l}}{W_{p l}}\left(\frac{\varepsilon_{C S m}}{\varepsilon_{y}}-1\right)-\left(1-\frac{W_{e l}}{W_{p l}}\right) /\left(\frac{\varepsilon_{C S m}}{\varepsilon_{y}}\right)^{2}\right]
$$

Note that the exponent on the final term of Equation 6 is dependent upon the shape of the crosssection - a value of 2 applies to SHS/RHS [17].

Comparisons between the experimental and numerical results and the four design methods are shown in Tables 4-5, while Table 7 and Figures 14-15 summarise the comparisons with both experimental and numerical results. Considering the three international design specifications, the performance of the Eurocode [3] and American standard [1] regarding the prediction of flexural capacity is more accurate than the AS/NZS [2] standard. The AS/NZS generally underestimated the resistance of the simply supported beams by approximately $50 \%$ with a large scatter (mean $M_{\text {exp }} / M_{A S / N Z S}=1.47$ and coefficient of variation $(\mathrm{COV})=0.20$ for specimens with slenderness less 
than 0.68; considering all specimens, the mean $M_{\text {exp }} / M_{A S / N Z S}=1.39$ and COV $=0.21$ ), as shown in Table 7. Meanwhile, the AA and EC9 provide better predictions with mean values of 1.33 and 1.22 with a corresponding COV of 0.18 and 0.11 for the experimental-to-predicted moment ratios $M_{\text {exp }} / M_{A A}$ and $M_{\text {exp }} / M_{E C 9}$ of non-slender sections $\left(\bar{\lambda}_{p} \leq 0.68\right)$, respectively, while considering the full range of specimens, the mean values are 1.27 and 1.21 with $\mathrm{COV}$ of 0.19 and 0.11 for $M_{\text {exp }} / M_{A A}$ and $M_{e x p} / M_{E C 9}$, respectively. EC9 (Annex F) provides the most consistent prediction among the three specifications. The predictions of these specifications are particularly conservative for the stocky sections, as presented in Tables 4 and 5 and Figures 14 and 15. The CSM approach, which only applied to non-slender sections, given a mean $M_{\text {exp }} / M_{c s m}=1.12$ and $\mathrm{COV}=0.11$ and provides a more accurate prediction of the bending capacity, with up to approximately $30 \%$ increases in capacity compared to the AS/NZS predictions, and more than $20 \%$ increases compared to the AA predictions. These improvements are linked to the deformation based approach of the CSM and the systematic use of strain hardening.

\section{CONCLUSIONS}

Two series of experiments on aluminium alloy hollow section beams, consisting of 14 three-point bending tests and 15 four-point bending tests and considering two material grades - 6061-T6 and 6063-T5, have been presented. The test specimens were of non-slender proportions, and were mostly Class 1 sections according to Eurocode 9 [3]. Measured geometric and material properties, together with the load-deflection curves from the test specimens have been reported herein. Failure modes of local buckling, material yielding and tensile fracture were observed in the tests. A further 33 three-point bending test results and 18 four-point bending test results on both slender and non-slender sections were collected from the literature and analyses. FE models were developed and validated against the experiments, after which they were employed in the parametric study to generate 132 numerical results. The plane slenderness ratio $b / t$ of the cross- 
sections has been extended beyond the tested range to a wider range (4.25 - 55.14) in the parametric study. The combined data set from the tests and the numerical simulations were used to assess the accuracy of three international design specifications: the Aluminum Design Manual [1], the Australian/New Zealand Standard [2] and Eurocode 9 [3] and the CSM for predicting the moment capacity of simply supported aluminium alloy beams. The results revealed that the three design specifications generally underestimate the observed moment resistance, especially for stocky sections, where capacities well beyond the fully plastic moment resistance were typically achieved in the tests. Through a deformation based approach that incorporated strain hardening, the continuous strength method was shown to offer improved predictions of capacity, up to $30 \%$ beyond those achieved in current specifications.

\section{Acknowledgements}

The research work in this study was supported by a grant from The University of Hong Kong under the seed funding program for basic research. The authors are also grateful to Mr Mantat Lin for his assistance in the experimental program as part of his final year undergraduate research project at The University of Hong Kong.

\section{Notation}

$B$

$=$ Section width

$b \quad=$ Flat width of flange

$\mathrm{COV} \quad=$ Coefficient of variation

E $\quad$ = Young's modulus

$E_{\text {sh }} \quad=$ Strain hardening modulus

$f_{y} \quad=$ Yield strength, taken as the $0.2 \%$ proof strength 
$=$ Ultimate tensile strength

$H$

$=$ Section depth

$h$

$=$ Flat depth of web

$L$

$=$ Member length

$M_{A A}$

= Ultimate moment capacity predicted by the AA (2010)

$M_{A S / N Z S}$

= Ultimate moment capacity predicted by the AS/NZS (1997)

$M_{c s m}$

= Ultimate moment capacity predicted by the CSM

$M_{E C 9}$

= Ultimate moment capacity predicted by Annex F of EC9 (2007)

$M_{e l}$

$=W_{e l} f_{y}$ is the elastic moment capacity

$M_{\exp }$

$=$ Experimental ultimate moment

$M_{F E}$

= Ultimate moment capacities of simulated models

$M_{p l}$

$=W_{p l} f_{y}$ is the plastic moment capacity

$n$

$=$ Exponent in Ramberg-Osgood expression

$R$

$=$ Rotation capacity

$=$ Wall thickness

$W_{\text {eff }}$

$=$ Elastic modulus of effective section

$W_{e l}$

$=$ Elastic section modulus

$W_{p l}$

$=$ Plastic section modulus

$\varepsilon_{c s m}$

$\varepsilon_{u}$

$\varepsilon_{y}$

$\kappa_{p l}$

$\kappa_{\text {rot }}$

$\bar{\lambda}_{p}$

$\theta_{p l}$

= CSM limiting strain

$=$ Strain at ultimate tensile stress

$=f_{y} / E$ is the yield strain

$=$ Elastic curvature corresponding to the plastic moment $M_{p l}$

$=$ Curvature at the point where the moment resistance drops back below $M_{p l}$

$=$ Cross-section/plate slenderness

= Elastic rotation corresponding to the plastic moment $M_{p l}$ 
$=$ Rotation at the point where the moment resistance drops back below $M_{p l}$

$\sigma_{c r}$ $=$ Elastic buckling stress 


\section{References}

[1] Aluminum Association (AA). (2010). Aluminum design manual. Washington, D.C.

[2] Australian/New Zealand Standard (AS/NZS). (1997). “Aluminum structures part 1: Limit state design.” AS/NZS 1664.1:1997, Standards Australia, Sydney, Australia.

[3] European Committee for Standardization (EC9) (2007). "Eurocode 9: Design of aluminium structures-Part 1-1: General rules-General rules and rules for buildings.” BS EN 1999-11:2007, CEN.

[4] Dumont, C. and Hill, H.N. (1940). "Lateral stability of equal flanged aluminum alloy I-beams subjected to pure bending.” NACA TN 770.

[5] Lai, Y.F.W. and Nethercot, D.A. (1992). "Strength of aluminium members containing local transverse welds.” Engineering Structures 14(4), 241-254.

[6] Moen, L.A., Hopperstad, O.S. and Langseth M. (1999). "Rotational capacity of aluminium beams under moment gradient. I: experiments.” Journal of Structural Engineering, ASCE 125(8), 910-920.

[7] Moen, L.A., De Matteis, G., Hopperstad, O.S., Langseth, M., Landolfo, R. and Mazzolani, F.M. (1999). "Rotational capacity of aluminium beams under moment gradient. II: numerical simulations.” Journal of Structural Engineering ASCE, 125(8), 921-929.

[8] De Matteis, G. Moen, L.A., Langseth, M., Landolfo, R., Hopperstad, O.S. and Mazzolani, F.M. (2001), "Cross-Sectional Classification for aluminium beams: a parametric study.” Journal of Structural Engineering, ASCE, 127 (3), 271-279.

[9] De Matteis, G., Landolfo, R., Manganiello, M. and Mazzolani, F.M. (2004), "Inelastic behaviour of I-shaped aluminium beams: numerical analysis and cross-sectional classification.” Computers and Structures, 82 (23-26), 2157-2171.

[10] Manganiello, M., De Matteis, G. and Landolfo R. (2006). "Inelastic flexural strength of aluminium alloy structures.” Engineering Structures, 28(4), 593-608.

[11] Eberwien, U. and Valtinat, G. (2001) "The fullness method: a direct procedure for calculation of the bending moment of a symmetrical aluminium cross section.” Proceedings of the eighth international conference in aluminium (INALCO), 3.3.1-3.3.10, Munich, Germany (March 23-28, 2001).

[12] Schafer, B.W. and Peköz, T. (1998). "Direct strength prediction of cold-formed steel members using numerical elastic buckling solutions.” Proceeding of 14th Int. specialty conference on cold-formed steel structures. 137-144, Rolla, Mo, USA (October, 1998).

[13] Zhu, J.H. and Young, B. (2009). "Design of aluminum alloy flexural members using direct strength method.” Journal of Structural Engineering, ASCE 135(5), 558-566. 
[14] Gardner, L. and Ashraf, M. (2006). "Structural design for non-linear metallic materials." Engineering Structures 28(6), 926-934.

[15] Kim, Y. and Peköz, P. (2010). "Ultimate flexural strength of aluminum sections.” Thinwalled structures 48(10-11), 857-865.

[16] Gardner, L. (2008). “The continuous strength method”, Proceedings of the Institution of Civil Engineers, Structures \& Buildings 161(3), 127-133.

[17] Gardner, L., Wang, F. and Liew, A. (2011). "Influence of strain hardening on the behaviour and design of steel structures.” International Journal of Structural Stability and Dynamics 11(5), 855-875.

[18] Ashraf, M. and Young, B. (2011). "Design formulations for non-welded and welded aluminium columns using Continuous Strength Method.” Engineering Structures 33(12), 31973207.

[19] Afshan, S. and Gardner, L. (2013) "The continuous strength method for structural stainless steel design” Thin-walled Structures, 68(2013): 42-49.

[20] Su, M., Young, B. and Gardner, L. (in press) “Testing and design of aluminium alloy crosssections in compression.” Journal of Structural Engineering, ASCE.

[21] Zhu, J.H. and Young, B. (2006). "Experimental investigation of aluminum alloy thin-walled tubular members in combined compression and bending." Journal of Structural Engineering, ASCE 132(12),1955-1966.

[22] Australian Standard (AS). (2007). "Methods for tensile testing of metals.” AS 1391-2007, Standards Association of Australia, Sydney, Australia.

[23] American Society for Testing and Materials (ASTM). (1997). "Standard test methods for tension testing of metallic materials.” E8M-97, West Conshohocken, Pa.

[24] American Society for Testing and Materials (ASTM). (2010). "Standard test method for indentation hardness of aluminum alloys by means of a Webster hardness gage.” B647-10, West Conshohocken, Pa.

[25] ABAQUS analysis user’s manual, version 6.10-1. ABAQUS Inc., 2010.

[26] Mazzolani, F.M. (1995), Aluminium alloy structures $2^{\text {nd }}$. E\&FN Spon Press.

[27] Chan, T.M. and Gardner, L. (2008). "Bending strength of hot-rolled elliptical hollow sections.” Journal of Construction Steel Research 64(9), 971-986.

[28] Theofanous, M., Chan, T.M. and Gardner, L. (2009). "Flexural behaviour of stainless steel oval hollow sections.” Thin-walled Structures 47(6-7), 776-787.

[29] Lay, M.G. and Galambos, T.V. (1965). "Inelastic steel beams under uniform moment." Journal of the Structural Division, ASCE 91(6), 67-93. 
[30] Lay, M.G. and Galambos, T.V. (1967). “Inelastic beams under moment gradient.” Journal of the Structural Division, ASCE 93(1), 381-99.

[31] Kuhlmann, U. (1989). "Definition of flange slenderness limits on the basis of rotation capacity values.” Journal of Constructional Steel Research 14(1), 21-40.

[32] Li, Z. and Schafer, B. W. (2010) "Buckling analysis of cold-formed steel members with general boundary conditions using CUFSM: conventional and constrained finite strip methods” Proceedings of the 20th International Specialty Conference on Cold-Formed Steel Structures, 1731, St. Louis, USA.

[33] Seif, M. and Schafer, B.W. (2010). “Local buckling of structural steel shapes.” Journal of Constructional Steel Research 66(10), 1232-1247. 
Table 1. Measured three-point bending specimen dimensions and material properties from tensile coupon tests

\begin{tabular}{|c|c|c|c|c|c|c|c|c|c|}
\hline Specimen & $\begin{array}{c}B \\
(\mathrm{~mm})\end{array}$ & $\begin{array}{c}H \\
(\mathrm{~mm})\end{array}$ & $\begin{array}{c}t \\
(\mathrm{~mm})\end{array}$ & $\begin{array}{c}L \\
(\mathrm{~mm})\end{array}$ & $\begin{array}{c}E \\
(\mathrm{GPa})\end{array}$ & $\begin{array}{c}f_{y} \\
(\mathrm{MPa})\end{array}$ & $\begin{array}{c}f_{u} \\
(\mathrm{MPa})\end{array}$ & $n$ & $\begin{array}{l}\text { Webster } \\
\text { hardness }\end{array}$ \\
\hline $\mathrm{H} 70 \times 55 \times 4.2 \mathrm{~B} 3$ & 69.8 & 55.2 & 4.09 & 694.8 & 67 & 207 & 222 & 16 & 13 \\
\hline $\mathrm{H} 55 \times 70 \times 4.2 \mathrm{~B} 3$ & 54.7 & 69.8 & 4.09 & 693.4 & 67 & 207 & 222 & 16 & 13 \\
\hline H95×50×10.5B3 & 94.7 & 49.6 & 10.34 & 695.0 & 68 & 229 & 242 & 11 & 11 \\
\hline $\mathrm{H} 50 \times 95 \times 10.5 \mathrm{~B} 3$ & 49.5 & 94.6 & 10.34 & 693.0 & 68 & 229 & 242 & 11 & 12 \\
\hline H64×64×3.0B3 & 63.9 & 63.8 & 2.89 & 692.7 & 67 & 232 & 245 & 10 & 12 \\
\hline H120×120×9.0B3 & 120.0 & 119.9 & 8.90 & 691.4 & 65 & 225 & 234 & 13 & 12 \\
\hline H120×70×10.5B3 & 119.8 & 69.8 & 10.28 & 691.4 & 68 & 226 & 238 & 10 & 12 \\
\hline H70×120×10.5B3 & 69.8 & 119.8 & 10.26 & 691.8 & 68 & 226 & 238 & 10 & 12 \\
\hline $\mathrm{H} 70 \times 55 \times 4.2 \mathrm{~B} 3-\mathrm{R}$ & 69.8 & 54.8 & 4.07 & 694.1 & 65 & 193 & 207 & 22 & 12 \\
\hline H50×95×10.5B3-R & 49.5 & 94.7 & 10.33 & 692.8 & 68 & 229 & 242 & 11 & 11 \\
\hline H64×64×3.0B3-R & 63.9 & 63.9 & 2.83 & 696.3 & 67 & 232 & 245 & 10 & 12 \\
\hline N120×70×10.5B3 & 120.0 & 69.9 & 10.4 & 689.1 & 71 & 139 & 194 & 9 & 10 \\
\hline N70×120×10.5B3 & 69.9 & 119.9 & 10.4 & 688.1 & 71 & 139 & 194 & 9 & 10 \\
\hline $\mathrm{N} 120 \times 120 \times 9.0 \mathrm{~B} 3$ & 119.9 & 119.9 & 8.9 & 692.8 & 69 & 181 & 228 & 9 & 11 \\
\hline Q1-1m-1 & 99.6 & 100.3 & 5.91 & 1000.0 & 69 & 316 & 324 & --- & $\begin{array}{l}-- \\
--\end{array}$ \\
\hline $\mathrm{Q} 1-1 \mathrm{~m}-2^{\#}$ & 99.6 & 100.3 & 5.91 & 1000.0 & 69 & 316 & 324 & --- & --- \\
\hline Q1-2m-1 & 99.6 & 100.3 & 5.91 & 2000.0 & 69 & 316 & 324 & --- & --- \\
\hline Q1-2m-3 & 99.6 & 100.3 & 5.91 & 2000.0 & 69 & 316 & 324 & --- & --- \\
\hline Q2-1m-1 $1^{\#}$ & 100.0 & 100.0 & 5.91 & 1000.0 & 67 & 177 & 284 & --- & --- \\
\hline Q2-1m-2 & 100.0 & 100.0 & 5.91 & 1000.0 & 67 & 177 & 284 & --- & --- \\
\hline Q2-2m-1 & 100.0 & 100.0 & 5.91 & 2000.0 & 67 & 177 & 284 & --- & --- \\
\hline Q2-2m-2 & 100.0 & 100.0 & 5.91 & 2000.0 & 67 & 177 & 283 & --- & --- \\
\hline Q3-1m-1 & 100.0 & 99.7 & 2.87 & 1000.0 & 67 & 120 & 221 & --- & --- \\
\hline Q3-1m-2 & 100.0 & 99.7 & 2.87 & 1000.0 & 67 & 120 & 221 & --- & --- \\
\hline Q3-2m-1 & 100.0 & 99.7 & 2.87 & 2000.0 & 67 & 120 & 221 & --- & --- \\
\hline Q3-2m-3 & 100.0 & 99.7 & 2.87 & 20000 & 67 & 120 & 221 & --- & --- \\
\hline $\mathrm{Q} 4-2 \mathrm{~m}-1^{\#}$ & 100.1 & 100.0 & 5.97 & 2000.0 & 67 & 314 & 333 & --- & --- \\
\hline $\mathrm{Q} 4-2 \mathrm{~m}-2^{\#}$ & 100.1 & 100.0 & 5.97 & 2000.0 & 67 & 314 & 333 & --- & --- \\
\hline $\mathrm{R} 1-1 \mathrm{~m}-1^{\#}$ & 60.0 & 119.4 & 2.45 & 1000.0 & 67 & 289 & 302 & --- & --- \\
\hline $\mathrm{R} 1-2 \mathrm{~m}-1^{\#}$ & 60.0 & 119.4 & 2.45 & 2000.0 & 67 & 289 & 302 & --- & --- \\
\hline $\mathrm{R} 1-2 \mathrm{~m}-2^{\#}$ & 60.0 & 119.4 & 2.45 & 2000.0 & 67 & 289 & 302 & --- & --- \\
\hline $\mathrm{R} 1-3 \mathrm{~m}-1^{\#}$ & 60.0 & 119.4 & 2.45 & 3000.0 & 67 & 289 & 302 & --- & --- \\
\hline $\mathrm{R} 1-3 \mathrm{~m}-2^{\#}$ & 60.0 & 119.4 & 2.45 & 3000.0 & 67 & 289 & 302 & --- & --- \\
\hline R2-1m-1 & 60.1 & 100.0 & 2.93 & 1000.0 & 66 & 281 & 290 & --- & --- \\
\hline $\mathrm{R} 2-1 \mathrm{~m}-2^{\#}$ & 60.1 & 100.0 & 2.93 & 1000.0 & 66 & 281 & 290 & --- & --- \\
\hline $\mathrm{R} 2-2 \mathrm{~m}-1^{\#}$ & 60.1 & 100.0 & 2.93 & 2000.0 & 66 & 281 & 290 & --- & --- \\
\hline $\mathrm{R} 2-2 \mathrm{~m}-2^{\#}$ & 60.1 & 100.0 & 2.93 & 2000.0 & 66 & 281 & 290 & --- & --- \\
\hline $\mathrm{R} 2-3 \mathrm{~m}-1^{\#}$ & 60.1 & 100.0 & 2.93 & 3000.0 & 66 & 281 & 290 & --- & --- \\
\hline $\mathrm{R} 2-3 \mathrm{~m}-2^{\#}$ & 60.1 & 100.0 & 2.93 & 3000.0 & 66 & 281 & 290 & --- & --- \\
\hline $\mathrm{I} 1-2 \mathrm{~m}-1^{\#}$ & 119.9 & 120.2 & 7.96 & 1000.0 & 67 & 312 & 324 & --- & --- \\
\hline $\mathrm{I} 2-1 \mathrm{~m}-1^{\#}$ & 70.0 & 80.35 & 4.97 & 1000.0 & 67 & 279 & 301 & --- & --- \\
\hline $\mathrm{I} 2-1 \mathrm{~m}-2^{\#}$ & 70.0 & 80.35 & 4.97 & 1000.0 & 67 & 279 & 301 & --- & --- \\
\hline $\mathrm{I} 2-1 \mathrm{~m}-3^{\#}$ & 70.0 & 80.35 & 4.97 & 1000.0 & 67 & 279 & 301 & --- & --- \\
\hline $\mathrm{I} 2-2 \mathrm{~m}-1^{\#}$ & 70.0 & 80.35 & 4.97 & 2000.0 & 67 & 279 & 301 & --- & --- \\
\hline $\mathrm{I} 2-2 \mathrm{~m}-2^{\#}$ & 70.0 & 80.35 & 4.97 & 2000.0 & 67 & 279 & 301 & --- & --- \\
\hline $\mathrm{I} 2-2 \mathrm{~m}-3^{\#}$ & 70.0 & 80.35 & 4.97 & 2000.0 & 67 & 279 & 301 & --- & --- \\
\hline $\mathrm{I} 2-3 \mathrm{~m}-1^{\#}$ & 70.0 & 80.35 & 4.97 & 3000.0 & 67 & 279 & 301 & --- & --- \\
\hline
\end{tabular}

${ }^{\#}$ Test results from Moen et al. [6]

--- Data are not available 
Table 2. Measured four-point bending specimen dimensions and material properties from tensile coupon tests

\begin{tabular}{|c|c|c|c|c|c|c|c|c|c|}
\hline Specimen & $\begin{array}{c}B \\
(\mathrm{~mm})\end{array}$ & $\begin{array}{c}H \\
(\mathrm{~mm})\end{array}$ & $\begin{array}{c}t \\
(\mathrm{~mm})\end{array}$ & $\begin{array}{c}L \\
(\mathrm{~mm})\end{array}$ & $\begin{array}{c}E \\
(\mathrm{GPa})\end{array}$ & $\begin{array}{c}f_{y} \\
(\mathrm{MPa})\end{array}$ & $\begin{array}{c}f_{u} \\
(\mathrm{MPa})\end{array}$ & $n$ & $\begin{array}{l}\text { Webster } \\
\text { hardness }\end{array}$ \\
\hline H70×55×4.2B4 & 69.9 & 54.9 & 4.09 & 990.0 & 67 & 207 & 222 & 16 & 14 \\
\hline H55×70×4.2B 4 & 54.9 & 69.9 & 4.10 & 993.1 & 67 & 207 & 222 & 16 & 14 \\
\hline H95×50×10.5B4 & 94.7 & 49.6 & 10.35 & 993.8 & 68 & 229 & 243 & 11 & 12 \\
\hline $\mathrm{H} 50 \times 95 \times 10.5 \mathrm{~B} 4$ & 49.6 & 94.7 & 10.37 & 988.3 & 68 & 229 & 243 & 11 & 12 \\
\hline H64×64×3.0B4 & 63.9 & 63.9 & 2.86 & 991.2 & 67 & 232 & 245 & 10 & 12 \\
\hline H120×120×9.0B4 & 120.0 & 112.0 & 8.92 & 995.8 & 65 & 225 & 234 & 13 & 12 \\
\hline $\mathrm{H} 120 \times 70 \times 10.5 B 4$ & 119.8 & 69.8 & 10.40 & 993.6 & 68 & 226 & 238 & 10 & 12 \\
\hline $\mathrm{H} 70 \times 120 \times 10.5 B 4$ & 69.9 & 119.8 & 10.30 & 996.5 & 68 & 226 & 238 & 10 & 12 \\
\hline H64×64×3.0B4-R & 63.8 & 63.9 & 2.87 & 993.4 & 67 & 232 & 245 & 10 & 12 \\
\hline H70×55×4.2B4-R & 70.0 & 54.9 & 4.08 & 989.5 & 67 & 207 & 222 & 16 & 14 \\
\hline $\mathrm{H} 55 \times 70 \times 4.2 \mathrm{~B} 4-\mathrm{R}$ & 54.9 & 70.0 & 4.09 & 989.5 & 67 & 207 & 222 & 16 & 14 \\
\hline $\mathrm{N} 50 \times 95 \times 10.5 \mathrm{~B} 4$ & 49.7 & 94.8 & 10.36 & 995.3 & 69 & 164 & 211 & 10 & 11 \\
\hline $\mathrm{N} 120 \times 70 \times 10.5 \mathrm{~B} 4$ & 119.8 & 69.9 & 10.42 & 989.1 & 71 & 139 & 194 & 9 & 10 \\
\hline N70×120×10.5B4 & 69.9 & 119.8 & 10.42 & 996.3 & 71 & 139 & 194 & 9 & 10 \\
\hline $\mathrm{N} 120 \times 120 \times 9.0 \mathrm{~B} 4$ & 119.9 & 119.9 & 8.91 & 993.2 & 69 & 181 & 228 & 9 & 11 \\
\hline $\mathrm{S} 1-\mathrm{PB}^{\#}$ & 44.6 & 44.6 & 1.14 & -- & 68 & 296 & 300 & $\begin{array}{ll}-- \\
--\end{array}$ & --- \\
\hline $\mathrm{R} 1-\mathrm{PB}^{\#}$ & 100.1 & 44.1 & 1.32 & --- & 70 & 260 & 276 & --- & --- \\
\hline R2-PB & 99.8 & 43.9 & 2.90 & --- & 69 & 275 & 283 & --- & --- \\
\hline R2-PB-R ${ }^{\#}$ & 99.8 & 44.0 & 2.91 & --- & 69 & 275 & 283 & --- & --- \\
\hline H $32 \times 32 \times 2 *$ & 32.0 & 32.0 & 1.94 & 1240.0 & 66 & 243 & 261 & --- & --- \\
\hline $\mathrm{H} 40 \times 40 \times 5 *$ & 39.9 & 39.9 & 4.85 & 1440.0 & 70 & 226 & 246 & --- & --- \\
\hline $\mathrm{H} 50 \times 50 \times 2 *$ & 50.7 & 50.7 & 1.95 & 1640.0 & 67 & 264 & 271 & --- & --- \\
\hline $\mathrm{H} 50 \times 50 \times 3 *$ & 50.5 & 50.5 & 3.09 & 1640.0 & 64 & 268 & 273 & --- & --- \\
\hline $\mathrm{H} 65 \times 65 \times 3 *$ & 64.1 & 64.1 & 2.99 & 1840.0 & 68 & 222 & 236 & --- & --- \\
\hline H76 $\times 76 \times 3^{*}$ & 76.1 & 76.1 & 3.10 & 1840.0 & 68 & 246 & 264 & --- & --- \\
\hline $\mathrm{H} 90 \times 90 \times 2 *$ & 88.2 & 88.2 & 1.75 & 2040.0 & 67 & 246 & 263 & --- & --- \\
\hline $\mathrm{H} 100 \times 100 \times 2 *$ & 102.0 & 102.0 & 2.31 & 2240.0 & 68 & 234 & 258 & --- & --- \\
\hline $\mathrm{H} 110 \times 110 \times 3^{*}$ & 111.6 & 111.6 & 3.13 & 2640.0 & 66 & 290 & 291 & --- & --- \\
\hline $\mathrm{H} 153 \times 153 \times 3^{*}$ & 153.6 & 153.6 & 3.36 & 3000.0 & 72 & 244 & 267 & --- & --- \\
\hline $\mathrm{N}-1000-\mathrm{P}-2^{\wedge}$ & 50.9 & 102.2 & 4.50 & 1200.0 & 71 & 373 & 430 & 33 & --- \\
\hline N-1000-P-3^ & 50.9 & 102.2 & 4.50 & 1200.0 & 71 & 373 & 430 & 33 & --- \\
\hline $\mathrm{N}-2000-\mathrm{P}-1^{\wedge}$ & 50.9 & 102.2 & 4.50 & 2200.0 & 71 & 373 & 430 & 33 & --- \\
\hline $\mathrm{N}-2000-\mathrm{P}-2^{\wedge}$ & 50.9 & 102.2 & 4.50 & 2200.0 & 71 & 373 & 430 & 33 & --- \\
\hline
\end{tabular}

\# Test results from Zhu and Young [21]

* Test results from Zhu and Young [13]

$\wedge$ Test results from Lai and Nethercot [5]

--- Data are not available 
Table 3. Comparison of moment and rotation capacity between the three-point and four-point bending tests.

\begin{tabular}{|c|c|c|c|c|c|}
\hline \multirow[b]{2}{*}{ Specimen } & \multicolumn{2}{|c|}{ Three-point bending } & \multicolumn{2}{|c|}{ Four-point bending } & \multirow{2}{*}{$\frac{M_{\exp }(B 3)}{M_{\text {exp }}(B 4)}$} \\
\hline & $\begin{array}{c}M_{\exp }(\mathrm{B} 3) \\
\quad(\mathrm{kNm})\end{array}$ & $\begin{array}{c}\text { Rotation } \\
\text { capacity } \\
\text { R (B3) }\end{array}$ & $\begin{array}{c}M_{\exp }(\mathrm{B} 4) \\
(\mathrm{kNm})\end{array}$ & $\begin{array}{l}\text { Rotation } \\
\text { capacity } \\
\text { R (B4) }\end{array}$ & \\
\hline $\mathrm{H} 70 \times 55 \times 4.2 \mathrm{~B} 3 / \mathrm{B} 4$ & 4.75 & 7.04 & 4.72 & 6.97 & 1.01 \\
\hline H55×70×4.2B3 /B4 & 6.76 & 9.00 & 6.49 & 7.70 & 1.04 \\
\hline H95×50×10.5B3/B4 & 12.09 & 6.02 & 10.35 & 7.25 & 1.17 \\
\hline $\mathrm{H} 50 \times 95 \times 10.5 B 3 / \mathrm{B} 4$ & 21.09 & 10.76 & 18.04 & 12.75 & 1.17 \\
\hline H64×64×3.0B3 /B4 & 4.10 & $2.71^{*}$ & 3.59 & 0 & 1.14 \\
\hline H120×120×9.0B3/B4 & 44.42 & 5.75 & 38.75 & --- & 1.15 \\
\hline H120×70×10.5B3/B4 & 23.59 & 6.58 & 19.66 & 6.12 & 1.20 \\
\hline $\mathrm{H} 70 \times 120 \times 10.5 \mathrm{~B} 3 / \mathrm{B} 4$ & 37.86 & 8.30 & 33.00 & 14.76 & 1.15 \\
\hline $\mathrm{N} 120 \times 70 \times 10.5 B 3 / \mathrm{B} 4$ & 20.73 & 11.44 & 14.97 & 17.29 & 1.38 \\
\hline $\mathrm{N} 70 \times 120 \times 10.5 \mathrm{~B} 3 / \mathrm{B} 4$ & 37.30 & 31.50 & 26.45 & 29.31 & 1.41 \\
\hline N120×120×9.0B3/B4 & 40.53 & 25.48 & 36.22 & 12.46 & 1.12 \\
\hline Mean & & & & & 1.18 \\
\hline
\end{tabular}

* Test moments did not drop back to $M_{p l}$ except specimen H64×64×3.0B3

--- Data are not available 
Table 4. Summary of comparisons between three-point bending test results and design strengths

\begin{tabular}{|c|c|c|c|c|c|c|c|c|}
\hline Specimen & $b / t$ & $\bar{\lambda}_{p}$ & $\frac{M_{\text {exp }}}{M_{e l}}$ & $\frac{M_{\text {exp }}}{M_{p l}}$ & $\frac{M_{\text {exp }}}{M_{A A}}$ & $\frac{M_{\text {exp }}}{M_{A S / N Z S}}$ & $\frac{M_{e x p}}{M_{E C 9}}$ & $\frac{M_{\text {exp }}}{M_{c s m}}$ \\
\hline $\mathrm{H} 70 \times 55 \times 4.2 \mathrm{~B} 3$ & 11.5 & 0.40 & 1.42 & 1.20 & 1.31 & 1.42 & 1.20 & 1.17 \\
\hline $\mathrm{H} 55 \times 70 \times 4.2 \mathrm{~B} 3$ & 15.1 & 0.32 & 1.41 & 1.15 & 1.58 & 1.77 & 1.15 & 1.08 \\
\hline H95×50×10.5B3 & 2.8 & 0.22 & 1.61 & 1.24 & 1.52 & 1.61 & 1.22 & 1.19 \\
\hline $\mathrm{H} 50 \times 95 \times 10.5 \mathrm{~B} 3$ & 7.2 & 0.10 & 1.73 & 1.29 & 1.46 & 1.73 & 1.28 & 1.24 \\
\hline H64×64×3.0B3 & 20.1 & 0.56 & 1.29 & 1.10 & 1.18 & 1.29 & 1.29 & 1.13 \\
\hline $\mathrm{H} 120 \times 120 \times 9.0 \mathrm{~B} 3$ & 11.5 & 0.34 & 1.45 & 1.20 & 1.32 & 1.45 & 1.21 & 1.16 \\
\hline $\mathrm{H} 120 \times 70 \times 10.5 \mathrm{~B} 3$ & 4.8 & 0.28 & 1.52 & 1.22 & 1.42 & 1.52 & 1.21 & 1.17 \\
\hline $\mathrm{H} 70 \times 120 \times 10.5 \mathrm{~B} 3$ & 9.7 & 0.17 & 1.68 & 1.30 & 1.45 & 1.68 & 1.29 & 1.25 \\
\hline $\mathrm{H} 70 \times 55 \times 4.2 \mathrm{~B} 3-\mathrm{R}$ & 11.5 & 0.40 & 1.44 & 1.22 & 1.33 & 1.44 & 1.21 & 1.18 \\
\hline H50×95×10.5B3-R & 7.2 & 0.10 & 1.70 & 1.27 & 1.44 & 1.70 & 1.26 & 1.22 \\
\hline H64×64×3.0B3-R & 20.5 & 0.57 & 1.37 & 1.16 & 1.25 & 1.37 & 1.37 & 1.21 \\
\hline $\mathrm{N} 120 \times 70 \times 10.5 \mathrm{~B} 3$ & 4.7 & 0.21 & 1.86 & 1.49 & 1.74 & 1.86 & 1.33 & 1.26 \\
\hline N70×120×10.5B3 & 9.5 & 0.13 & 2.30 & 1.78 & 1.98 & 2.30 & 1.59 & 1.50 \\
\hline $\mathrm{N} 120 \times 120 \times 9.0 \mathrm{~B} 3$ & 11.5 & 0.29 & 1.43 & 1.19 & 1.30 & 1.43 & 1.07 & 0.99 \\
\hline Q1-1m-1 & 15.0 & 0.49 & 1.16 & 0.97 & 1.06 & 1.16 & 1.16 & 0.98 \\
\hline Q1-1m-2 & 15.0 & 0.49 & 1.16 & 0.97 & 1.06 & 1.16 & 1.16 & 0.98 \\
\hline Q1-2m-1 & 15.0 & 0.49 & 1.13 & 0.95 & 1.03 & 1.13 & 1.13 & 0.95 \\
\hline Q1-2m-3 & 15.0 & 0.49 & 1.14 & 0.96 & 1.04 & 1.14 & 1.14 & 0.96 \\
\hline Q2-1m-1 & 14.9 & 0.37 & 1.37 & 1.15 & 1.25 & 1.37 & 1.15 & 0.96 \\
\hline $\mathrm{Q} 2-1 \mathrm{~m}-2^{\#}$ & 14.9 & 0.37 & 1.36 & 1.14 & 1.24 & 1.36 & 1.14 & 0.95 \\
\hline Q2-2m-1 & 14.9 & 0.37 & 1.32 & 1.11 & 1.20 & 1.32 & 1.11 & 0.92 \\
\hline Q2-2m-2 & 14.9 & 0.37 & 1.36 & 1.14 & 1.24 & 1.36 & 1.14 & 0.95 \\
\hline Q3-1m-1 & 32.8 & 0.65 & 1.06 & 0.92 & 1.01 & 1.06 & 1.07 & 1.01 \\
\hline Q3-1m-2 & 32.8 & 0.65 & 1.04 & 0.90 & 0.99 & 1.04 & 1.11 & 0.99 \\
\hline Q3-2m-1 & 32.8 & 0.65 & 1.03 & 0.89 & 0.98 & 1.03 & 1.10 & 0.98 \\
\hline Q3-2m-3 & 32.8 & 0.65 & 1.08 & 0.93 & 1.03 & 1.08 & 1.15 & 1.03 \\
\hline Q4-2m-1 & 14.8 & 0.49 & 1.20 & 1.01 & 1.09 & 1.20 & 1.20 & 1.00 \\
\hline Q4-2m-2 & 14.8 & 0.49 & 1.16 & 0.97 & 1.06 & 1.16 & 1.16 & 0.97 \\
\hline $\mathrm{R} 1-1 \mathrm{~m}-1^{\#}$ & 46.7 & 0.73 & 0.94 & 0.77 & 0.85 & 0.94 & 0.96 & --- \\
\hline $\mathrm{R} 1-2 \mathrm{~m}-1^{\#}$ & 46.7 & 0.73 & 0.94 & 0.77 & 0.85 & 0.94 & 0.96 & --- \\
\hline $\mathrm{R} 1-2 \mathrm{~m}-2^{\#}$ & 46.7 & 0.73 & 0.94 & 0.77 & 0.85 & 0.94 & 0.96 & --- \\
\hline $\mathrm{R} 1-3 \mathrm{~m}-1^{\#}$ & 46.7 & 0.73 & 0.88 & 0.72 & 0.80 & 0.88 & 0.90 & --- \\
\hline $\mathrm{R} 1-3 \mathrm{~m}-2^{\#}$ & 46.7 & 0.73 & 0.87 & 0.71 & 0.79 & 0.87 & 0.89 & --- \\
\hline $\mathrm{R} 2-1 \mathrm{~m}-1^{\#}$ & 32.1 & 0.59 & 1.15 & 0.95 & 1.02 & 1.11 & 1.15 & 1.01 \\
\hline $\mathrm{R} 2-1 \mathrm{~m}-2^{\#}$ & 32.1 & 0.59 & 1.15 & 0.95 & 1.02 & 1.11 & 1.15 & 1.01 \\
\hline R2-2m-1 & 32.1 & 0.59 & 1.14 & 0.94 & 1.01 & 1.10 & 1.14 & 1.00 \\
\hline $\mathrm{R} 2-2 \mathrm{~m}-2^{\#}$ & 32.1 & 0.59 & 1.17 & 0.96 & 1.04 & 1.13 & 1.17 & 1.03 \\
\hline $\mathrm{R} 2-3 \mathrm{~m}-1^{\#}$ & 32.1 & 0.59 & 1.20 & 0.99 & 1.07 & 1.16 & 1.20 & 1.05 \\
\hline $\mathrm{R} 2-3 \mathrm{~m}-2^{\#}$ & 32.1 & 0.59 & 1.19 & 0.98 & 1.06 & 1.15 & 1.19 & 1.04 \\
\hline $\mathrm{I} 1-2 \mathrm{~m}-1^{\#}$ & 20.5 & 0.57 & 1.02 & 0.91 & 0.98 & 1.02 & 1.16 & 0.94 \\
\hline $\mathrm{I} 2-1 \mathrm{~m}-1^{\#}$ & 14.2 & 0.51 & 1.21 & 1.06 & 1.14 & 1.29 & 1.16 & 1.05 \\
\hline $\mathrm{I} 2-1 \mathrm{~m}-2^{\#}$ & 14.2 & 0.51 & 1.17 & 1.02 & 1.10 & 1.25 & 1.13 & 1.02 \\
\hline $\mathrm{I} 2-1 \mathrm{~m}-3^{\#}$ & 14.2 & 0.51 & 1.17 & 1.02 & 1.10 & 1.25 & 1.14 & 1.02 \\
\hline $\mathrm{I} 2-2 \mathrm{~m}-1^{\#}$ & 14.2 & 0.51 & 1.16 & 1.01 & 1.09 & 1.23 & 1.15 & 1.01 \\
\hline $\mathrm{I} 2-2 \mathrm{~m}-2^{\#}$ & 14.2 & 0.51 & 1.17 & 1.02 & 1.10 & 1.25 & 1.14 & 1.02 \\
\hline $\mathrm{I} 2-2 \mathrm{~m}-3^{\#}$ & 14.2 & 0.51 & 1.19 & 1.04 & 1.12 & 1.27 & 1.11 & 1.04 \\
\hline $\mathrm{I} 2-3 \mathrm{~m}-1^{\#}$ & 14.2 & 0.51 & 1.13 & 0.99 & 1.06 & 1.20 & 1.14 & 0.98 \\
\hline Mean (Sections within $\bar{\lambda}_{p} \leq 0.68$ ) & & & 1.46 & 1.21 & 1.33 & 1.47 & 1.25 & 1.15 \\
\hline COV (Sections within $\bar{\lambda}_{p} \leq 0.68$ ) & & & 0.22 & 0.19 & 0.20 & 0.21 & 0.11 & 0.11 \\
\hline
\end{tabular}




\begin{tabular}{lcccccc} 
Mean (All cross-sections) & 1.37 & 1.14 & 1.29 & 1.41 & 1.24 & 1.15 \\
COV (All cross-sections) & 0.25 & 0.22 & 0.12 & 0.22 & 0.11 & 0.11 \\
\hline
\end{tabular}

\# Test results from Moen et al. [6]

--- Data are not available

Table 5. Summary of comparisons between four-point bending test results and design strengths

\begin{tabular}{|c|c|c|c|c|c|c|c|c|}
\hline Specimen & $b / t$ & $\bar{\lambda}_{p}$ & $\frac{M_{\text {exp }}}{M_{e l}}$ & $\frac{M_{e x p}}{M_{p l}}$ & $\frac{M_{\exp }}{M_{A A}}$ & $\frac{M_{\text {exp }}}{M_{\text {AS /NZS }}}$ & $\frac{M_{\text {exp }}}{M_{E C 9}}$ & $\frac{M_{\text {exp }}}{M_{c s m}}$ \\
\hline $\mathrm{H} 70 \times 55 \times 4.2 \mathrm{~B} 4$ & 11.4 & 0.66 & 1.13 & 0.95 & 1.31 & 1.43 & 0.95 & 0.92 \\
\hline $\mathrm{H} 55 \times 70 \times 4.2 \mathrm{~B} 4$ & 15.1 & 0.94 & 1.34 & 1.10 & 1.51 & 1.69 & 1.10 & 1.03 \\
\hline H95×50×10.5B4 & 2.8 & 1.32 & 1.38 & 1.06 & 1.30 & 1.38 & 1.04 & 1.01 \\
\hline $\mathrm{H} 50 \times 95 \times 10.5 B 4$ & 7.1 & 0.17 & 1.47 & 1.10 & 1.25 & 1.48 & 1.09 & 1.05 \\
\hline H64×64×3.0B4 & 20.4 & 0.23 & 1.14 & 0.97 & 1.04 & 1.14 & 1.14 & 1.00 \\
\hline $\mathrm{H} 120 \times 120 \times 9.0 \mathrm{~B} 4$ & 11.5 & 0.30 & 1.26 & 1.04 & 1.15 & 1.26 & 1.05 & 1.01 \\
\hline $\mathrm{H} 120 \times 70 \times 10.5 B 4$ & 4.7 & 0.43 & 1.25 & 1.01 & 1.17 & 1.25 & 1.00 & 0.97 \\
\hline $\mathrm{H} 70 \times 120 \times 10.5 \mathrm{~B} 4$ & 9.6 & 0.61 & 1.46 & 1.13 & 1.26 & 1.46 & 1.12 & 1.08 \\
\hline H64×64×3.0B4-R & 20.3 & 0.25 & 1.14 & 0.97 & 1.04 & 1.14 & 1.14 & 1.00 \\
\hline $\mathrm{H} 70 \times 55 \times 4.2 \mathrm{~B} 4-\mathrm{R}$ & 11.4 & 0.34 & 1.16 & 0.98 & 1.35 & 1.46 & 0.98 & 0.94 \\
\hline $\mathrm{H} 55 \times 70 \times 4.2 \mathrm{~B} 4-\mathrm{R}$ & 15.1 & 0.51 & 1.25 & 1.03 & 1.41 & 1.58 & 1.03 & 0.97 \\
\hline $\mathrm{N} 50 \times 95 \times 10.5 \mathrm{~B} 4$ & 7.2 & 0.89 & 1.81 & 1.35 & 1.53 & 1.79 & 1.24 & 1.16 \\
\hline N120×70×10.5B4 & 4.7 & 0.28 & 1.54 & 1.24 & 1.44 & 1.54 & 1.10 & 1.04 \\
\hline N70 $\times 120 \times 10.5 B 4$ & 9.5 & 0.37 & 1.88 & 1.45 & 1.62 & 1.88 & 1.30 & 1.23 \\
\hline $\mathrm{N} 120 \times 120 \times 9.0 \mathrm{~B} 4$ & 11.5 & 0.57 & 1.47 & 1.22 & 1.34 & 1.47 & 1.10 & 1.02 \\
\hline $\mathrm{S} 1-\mathrm{PB}^{\#}$ & 37.1 & 0.98 & 0.98 & 0.85 & 1.17 & 1.16 & 1.23 & --- \\
\hline $\mathrm{R} 1-\mathrm{PB}^{\#}$ & 31.4 & 0.22 & 0.63 & 0.58 & 1.30 & 1.32 & 1.18 & --- \\
\hline R2-PB ${ }^{\#}$ & 13.1 & 0.30 & 1.03 & 0.91 & 1.13 & 1.21 & 1.24 & --- \\
\hline R2-PB-R ${ }^{\#}$ & 13.1 & 0.46 & 1.01 & 0.89 & 1.11 & 1.18 & 1.22 & --- \\
\hline H $32 \times 32 \times 2 *$ & 14.5 & 0.79 & 1.27 & 1.06 & 1.16 & 1.27 & 1.06 & 1.04 \\
\hline $\mathrm{H} 40 \times 40 \times 5 *$ & 6.2 & 0.29 & 1.34 & 1.06 & 1.21 & 1.34 & 1.02 & 0.99 \\
\hline $\mathrm{H} 50 \times 50 \times 2 *$ & 24.0 & 0.36 & 1.07 & 0.91 & 1.00 & 1.07 & 1.11 & --- \\
\hline $\mathrm{H} 50 \times 50 \times 3 *$ & 14.3 & 0.47 & 1.20 & 1.01 & 1.10 & 1.20 & 1.01 & 1.01 \\
\hline $\mathrm{H} 65 \times 65 \times 3 *$ & 19.4 & 0.68 & 1.23 & 1.04 & 1.12 & 1.22 & 1.23 & 1.06 \\
\hline $\mathrm{H} 76 \times 76 \times 3^{*}$ & 22.5 & 0.96 & 1.09 & 0.93 & 1.00 & 1.09 & 1.09 & 1.02 \\
\hline $\mathrm{H} 90 \times 90 \times 2 *$ & 48.4 & 0.21 & 0.73 & 0.63 & 0.97 & 0.99 & 0.98 & --- \\
\hline $\mathrm{H} 100 \times 100 \times 2 *$ & 42.2 & 0.26 & 0.88 & 0.77 & 1.07 & 1.09 & 1.11 & --- \\
\hline $\mathrm{H} 110 \times 110 \times 3^{*}$ & 33.7 & 0.34 & 0.93 & 0.80 & 1.04 & 1.06 & 1.11 & --- \\
\hline $\mathrm{H} 153 \times 153 \times 3^{*}$ & 43.7 & 0.49 & 0.77 & 0.67 & 0.95 & 0.97 & 1.00 & --- \\
\hline $\mathrm{N}-1000-\mathrm{P}-2^{\wedge}$ & 20.7 & 0.70 & 1.65 & 1.17 & 1.43 & 1.65 & 1.31 & 1.06 \\
\hline N-1000-P-3^ & 20.7 & 0.27 & 1.68 & 1.20 & 1.46 & 1.68 & 1.34 & 1.09 \\
\hline N-2000-P-1^ & 20.7 & 0.33 & 1.48 & 1.05 & 1.29 & 1.48 & 1.18 & 0.96 \\
\hline $\mathrm{N}-2000-\mathrm{P}-2^{\wedge}$ & 20.7 & 0.43 & 1.52 & 1.08 & 1.32 & 1.52 & 1.21 & 0.98 \\
\hline Mean (Sections within $\bar{\lambda}_{p} \leq 0.68$ ) & & & 1.45 & 1.18 & 1.32 & 1.47 & 1.18 & 1.10 \\
\hline COV (Sections within $\bar{\lambda}_{p} \leq 0.68$ ) & & & 0.18 & 0.16 & 0.16 & 0.17 & 0.10 & 0.09 \\
\hline Mean (All cross-sections) & & & 1.30 & 1.07 & 1.25 & 1.37 & 1.18 & 1.10 \\
\hline COV (All cross-sections) & & & 0.25 & 0.22 & 0.17 & 0.20 & 0.09 & 0.09 \\
\hline
\end{tabular}

\footnotetext{
* Test results from Zhu and Young [21]

* Test results from Zhu and Young [13]

$\wedge$ Test results from Lai and Nethercot [5]

--- Data are not available
} 
Table 6. Comparison between experimental and numerical results

\begin{tabular}{|c|c|c|c|c|c|c|c|}
\hline Specimen & $\begin{array}{l}M_{\text {exp }} \\
(\mathrm{kNm})\end{array}$ & $\begin{array}{c}M_{F E} \\
(\mathrm{kNm})\end{array}$ & $\frac{M_{\text {exp }}}{M_{F E}}$ & Specimen & $\begin{array}{l}M_{\text {exp }} \\
(\mathrm{kN})\end{array}$ & $\begin{array}{c}M_{F E} \\
(\mathrm{kN})\end{array}$ & $\frac{M_{\exp }}{M_{F E}}$ \\
\hline $\mathrm{H} 70 \times 55 \times 4.2 \mathrm{~B} 3$ & 4.8 & 5.0 & 0.96 & $\mathrm{H} 70 \times 55 \times 4.2 \mathrm{~B} 4$ & 4.7 & 4.3 & 1.09 \\
\hline $\mathrm{H} 70 \times 55 \times 4.2 \mathrm{~B} 3-\mathrm{R}$ & 4.4 & 4.6 & 0.95 & $\mathrm{H} 70 \times 55 \times 4.2 \mathrm{~B} 4-\mathrm{R}$ & 4.8 & 4.3 & 1.11 \\
\hline $\mathrm{H} 55 \times 70 \times 4.2 \mathrm{~B} 3$ & 6.8 & 6.2 & 1.09 & $\mathrm{H} 55 \times 70 \times 4.2 \mathrm{~B} 4$ & 6.5 & 6.8 & 0.96 \\
\hline H95×50×10.5B3 & 12.1 & 11.9 & 1.02 & $\mathrm{H} 55 \times 70 \times 4.2 \mathrm{~B} 4-\mathrm{R}$ & 6.1 & 6.8 & 0.90 \\
\hline H50×95×10.5B3 & 21.1 & 22.0 & 0.96 & H95×50×10.5B4 & 10.4 & 10.5 & 0.99 \\
\hline $\mathrm{H} 50 \times 95 \times 10.5 \mathrm{~B} 3-\mathrm{R}$ & 20.8 & 21.4 & 0.97 & H50×95×10.5B 4 & 18.0 & 19.1 & 0.94 \\
\hline H64×64×3.0B3 & 4.1 & 4.3 & 0.95 & H64×64×3.0B4 & 3.6 & 3.8 & 0.95 \\
\hline H64×64×3.0B3-R & 4.3 & 4.4 & 0.98 & H64×64×3.0B4-R & 3.6 & 3.8 & 0.95 \\
\hline H120×120×9.0B3 & 44.4 & 44.4 & 1.00 & H120×120×9.0B 4 & 38.8 & 38.4 & 1.01 \\
\hline $\mathrm{H} 120 \times 70 \times 10.5 \mathrm{~B} 3$ & 23.6 & 25.4 & 0.93 & $\mathrm{H} 70 \times 120 \times 10.5 B 4$ & 33.0 & 35.5 & 0.93 \\
\hline $\mathrm{H} 70 \times 120 \times 10.5 \mathrm{~B} 3$ & 37.9 & 40.8 & 0.93 & $\mathrm{~N} 120 \times 70 \times 10.5 \mathrm{~B} 4$ & 15.0 & 17.2 & 0.87 \\
\hline $\mathrm{N} 120 \times 70 \times 10.5 \mathrm{~B} 3$ & 18.0 & 20.0 & 0.90 & $\mathrm{~N} 70 \times 120 \times 10.5 \mathrm{~B} 4$ & 26.5 & 28.2 & 0.94 \\
\hline \multirow[t]{3}{*}{$\mathrm{N} 70 \times 120 \times 10.5 \mathrm{~B} 3$} & 32.4 & 33.4 & 0.97 & $\mathrm{~N} 120 \times 120 \times 9.0 \mathrm{~B} 4$ & 36.2 & 35.5 & 1.02 \\
\hline & & Mean & 0.97 & & & Mean & 0.97 \\
\hline & & $\mathrm{COV}$ & 0.049 & & & $\mathrm{COV}$ & 0.071 \\
\hline
\end{tabular}

Table 7. Summary of comparisons between all experimental and numerical results with design strengths

\begin{tabular}{|c|c|c|c|c|}
\hline & $M_{\text {exp }}{ }^{\#}$ & $M_{\text {exp }}$ & $M_{\text {exp }} \#$ & $M_{\text {exp }} \#$ \\
\hline & $M_{A A}$ & $\overline{M_{A S / N Z S}}$ & $\overline{M_{E C 9}}$ & $\overline{M_{C S m}}$ \\
\hline Number of Specimens & $155(208)$ & 155 (208) & $155(208)$ & 155 \\
\hline Mean, $P_{m}$ & $1.33(1.27)$ & 1.47 (1.39) & $1.22(1.21)$ & 1.12 \\
\hline $\mathrm{COV}, V_{p}$ & $0.18(0.19)$ & $0.20(0.21)$ & $0.11(0.11)$ & 0.11 \\
\hline
\end{tabular}

Note that only 155 specimens are within the limits of applicability of the CSM, while a total of 208 results are covered by the three international specifications. Values in brackets refer to the full database of 208 tests

${ }^{\#} M_{\text {exp }}$ included both experimental and numerical results 


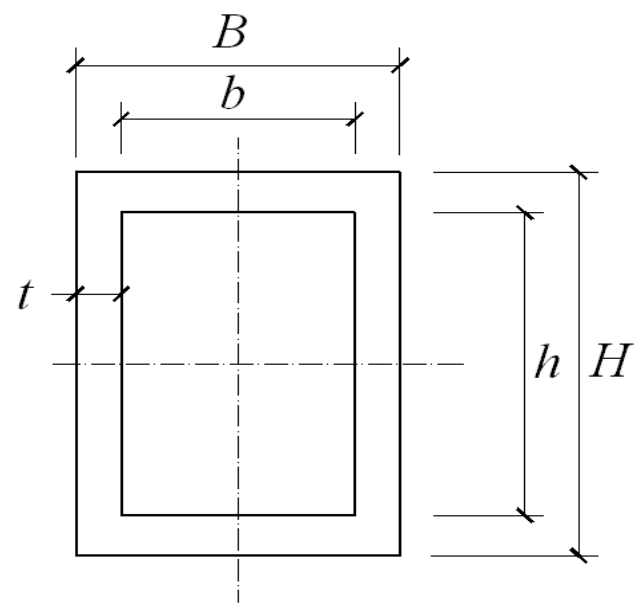

(a)

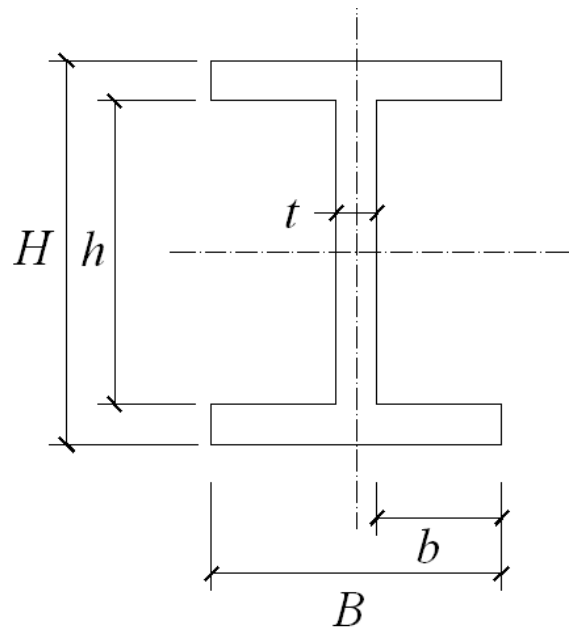

(b)

Figure 1. Definition of symbols for (a) SHS/RHS and (b) I-section 


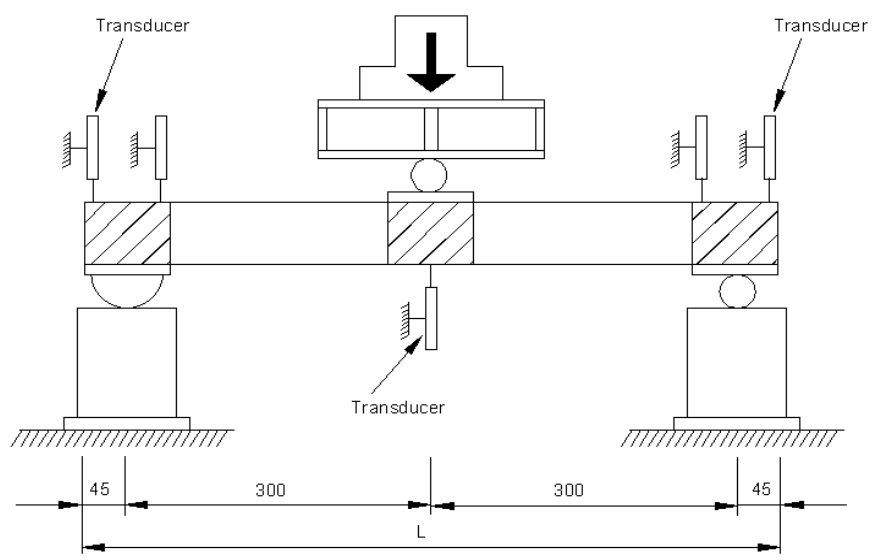

Figure 2. Schematic illustration of three-point bending test configuration (dimensions in mm)

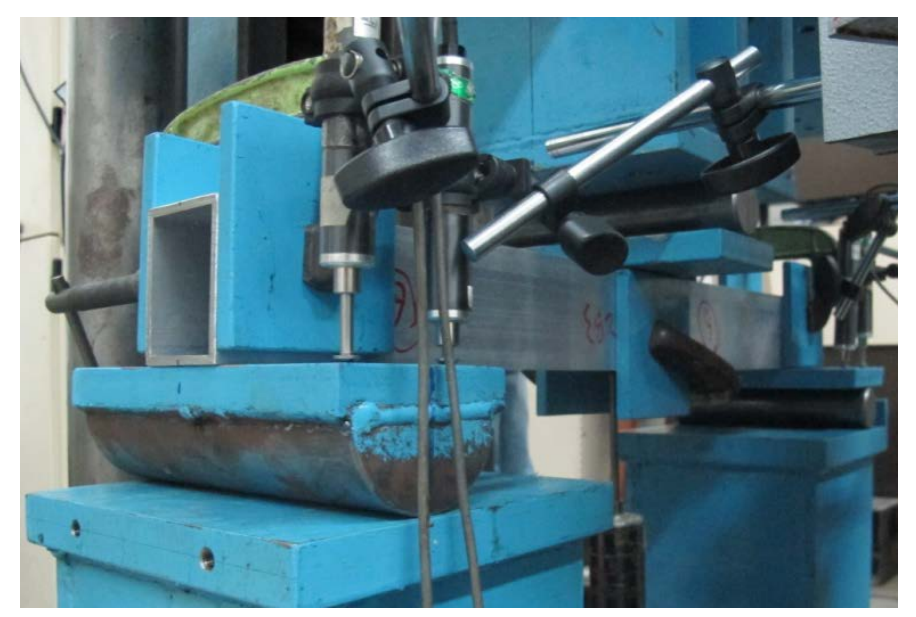

Figure 3. Experimental setup for three-point bending tests 


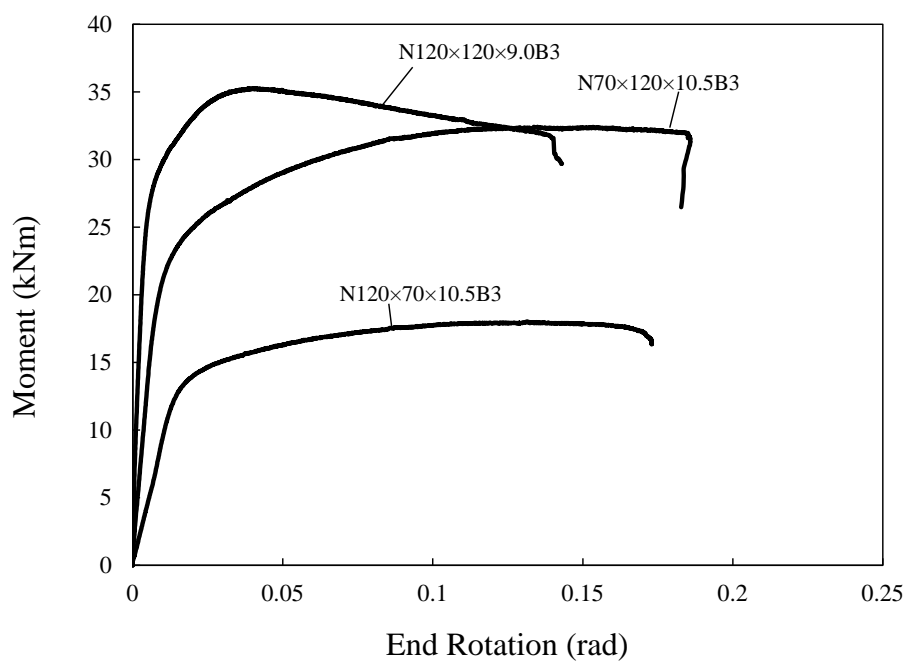

(a)

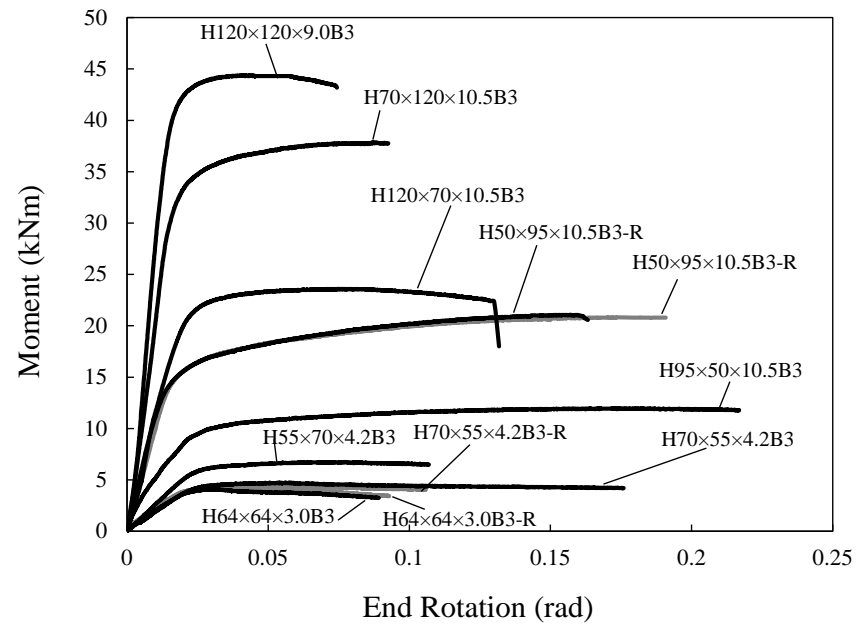

(b)

Figure 4. Moment-end rotation curves from three-point bending tests on (a) normal strength 6063-T5 aluminium alloy beams and (b) high strength 6061-T6 aluminium alloy beams 


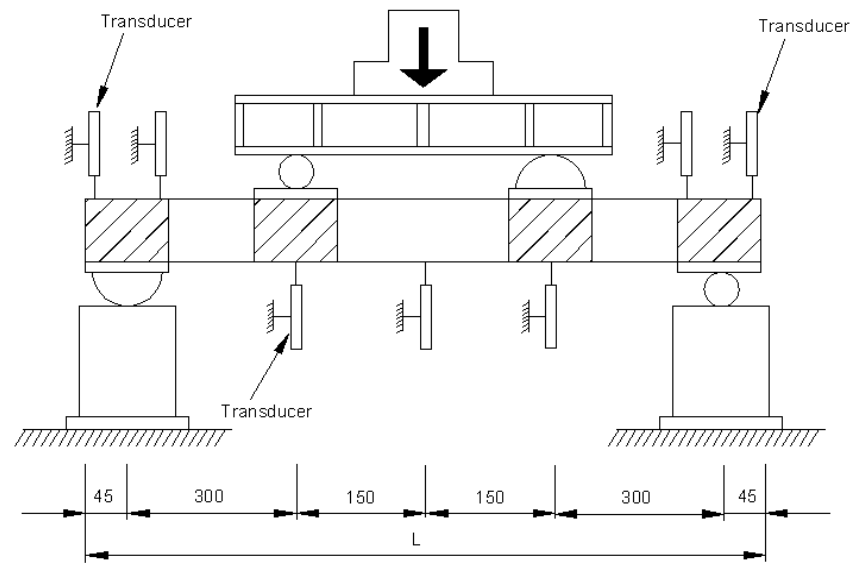

Figure 5. Schematic illustration of four-point bending test configuration (dimensions in mm)

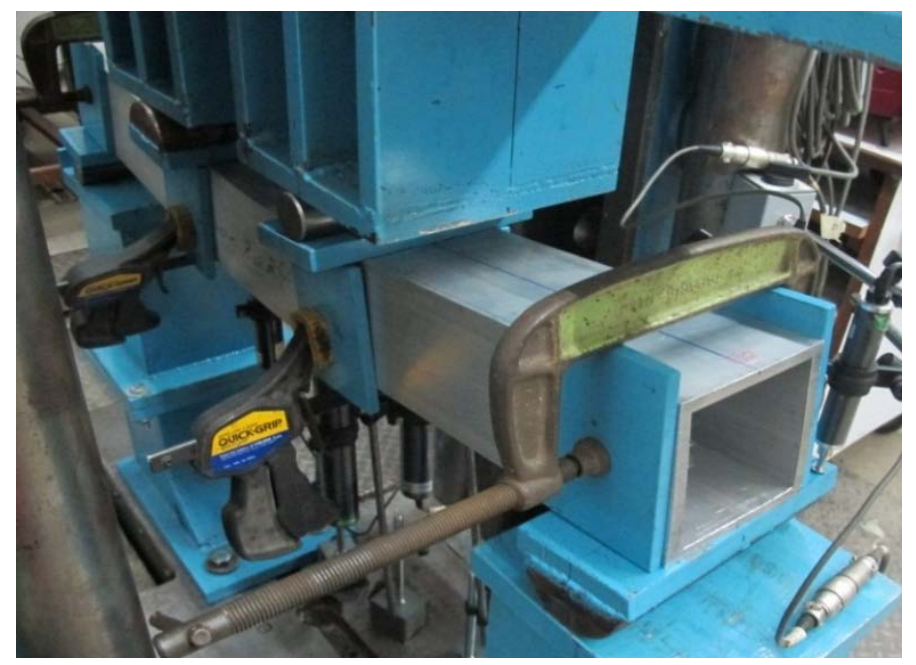

Figure 6. Experimental setup for four-point bending tests 


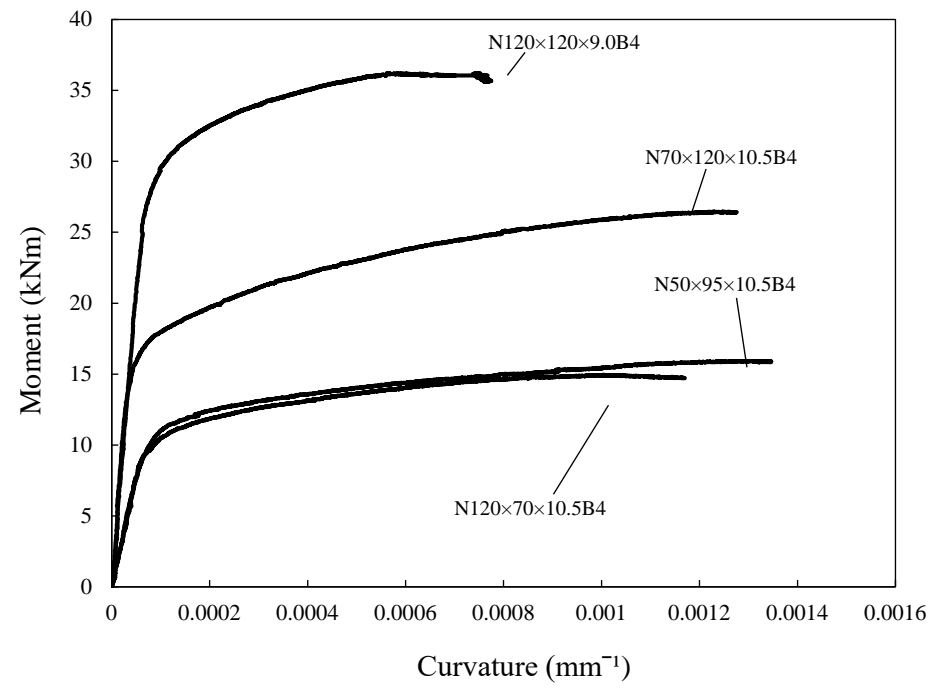

(a)

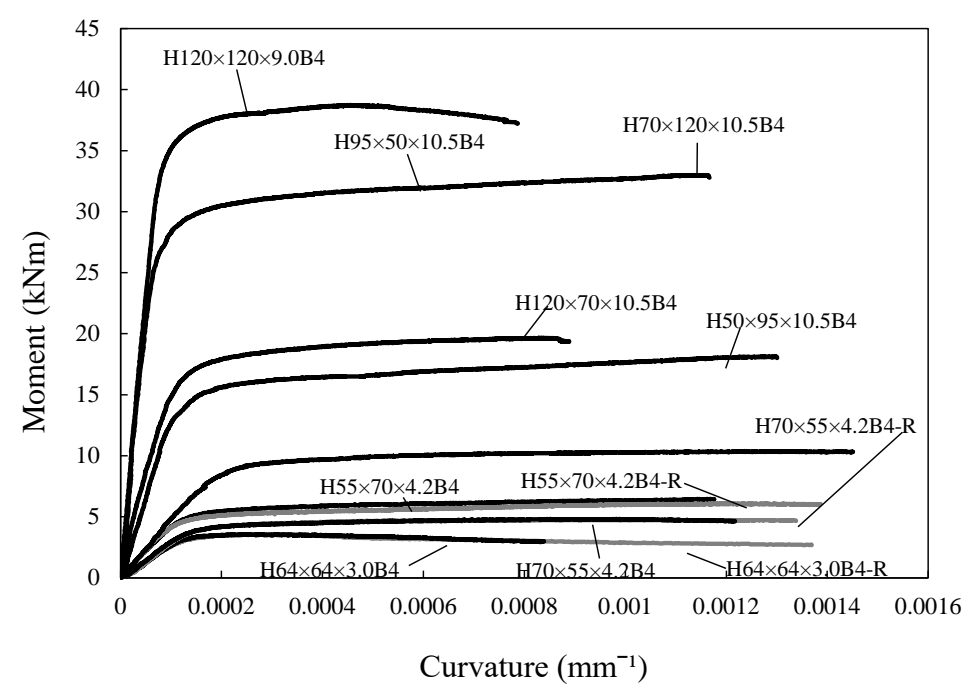

(b)

Figure 7. Moment-curvature curves from four-point bending tests on (a) normal strength 6063-T5 aluminium alloy beams and (b) high strength 6061-T6 aluminium alloy beams 


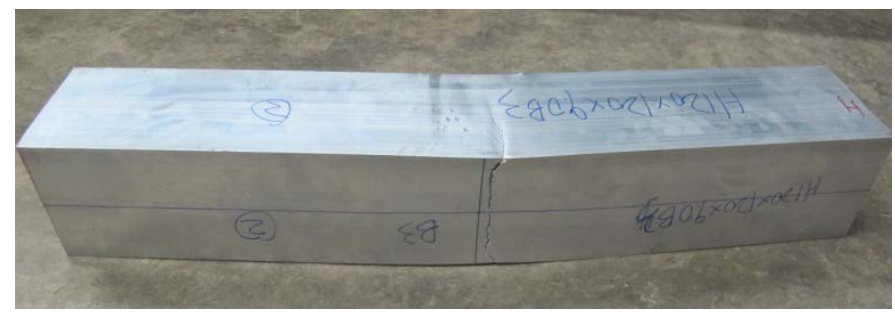

Figure 8. Material splitting (fracture) on the tension flange of specimen $\mathrm{H} 120 \times 120 \times 9.0 \mathrm{~B} 3$

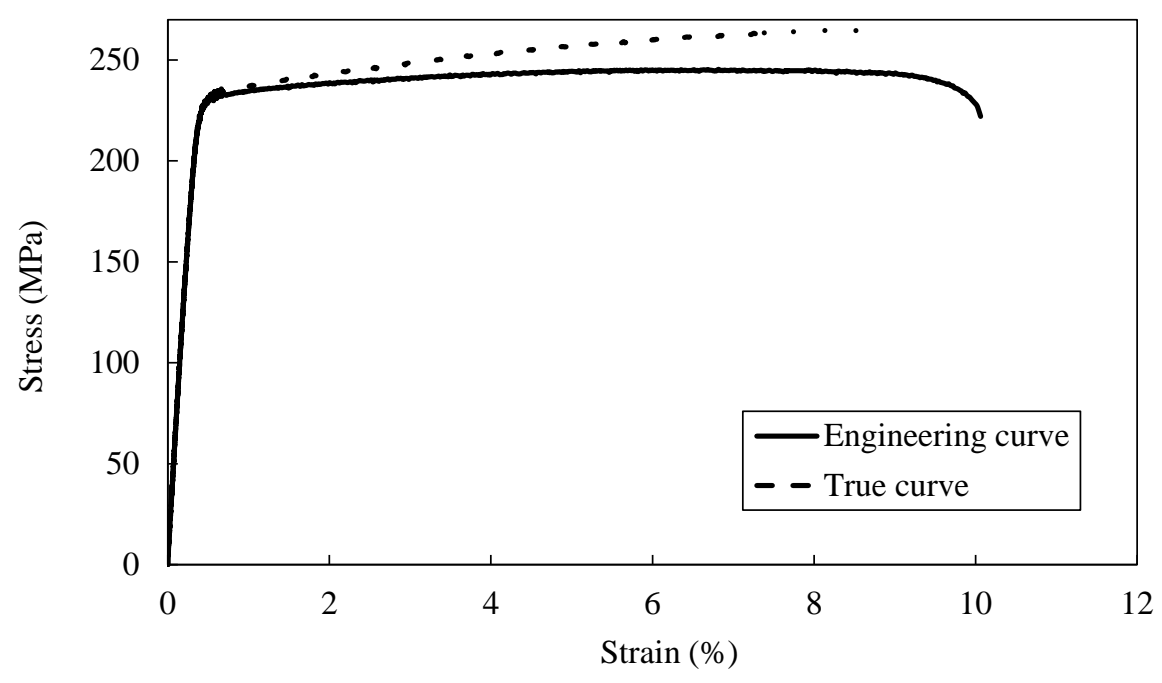

Figure 9. Material stress-strain curves for specimen H164×64×3.0B3 
Figure 10. A typical elastic local buckling mode

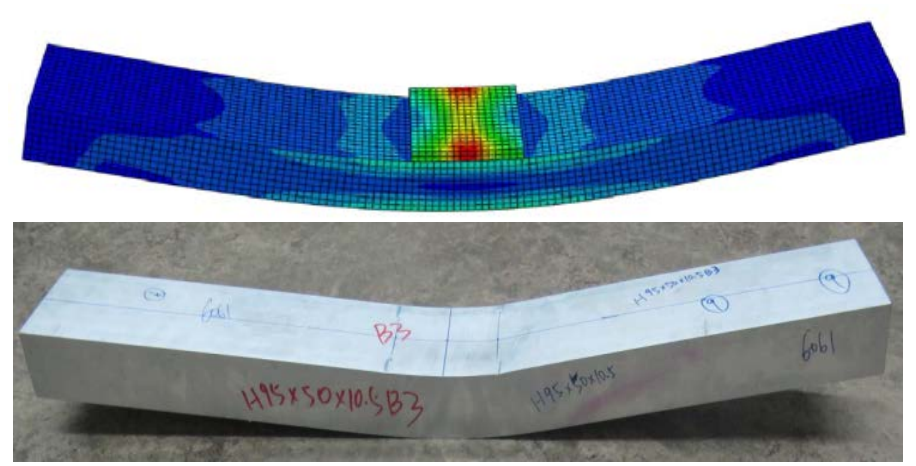

Figure 11. Three-point bending numerical and tested specimen $($ H95×50×9.0B3)

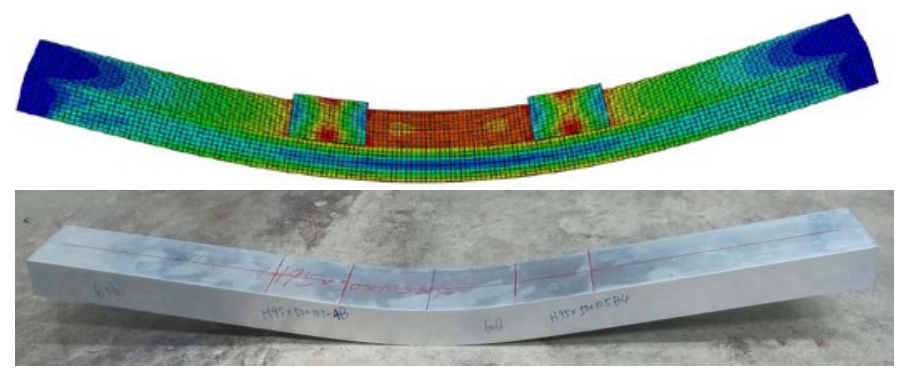

Figure 12. Four-point bending numerical and tested specimen $(\mathrm{H} 95 \times 50 \times 9.0 \mathrm{~B} 4)$ 


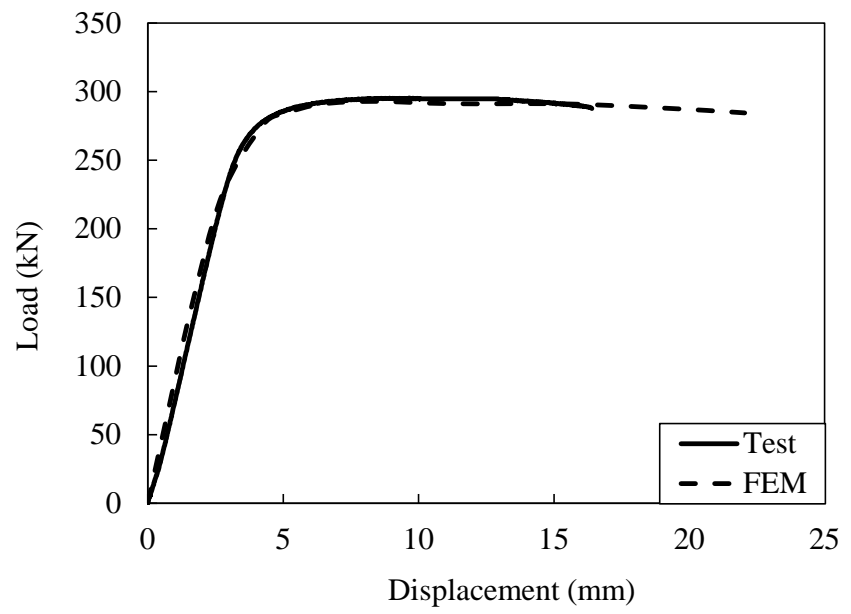

Figure 13. Experimental and numerical load-displacement curves for specimen H120×120×9.0B3 


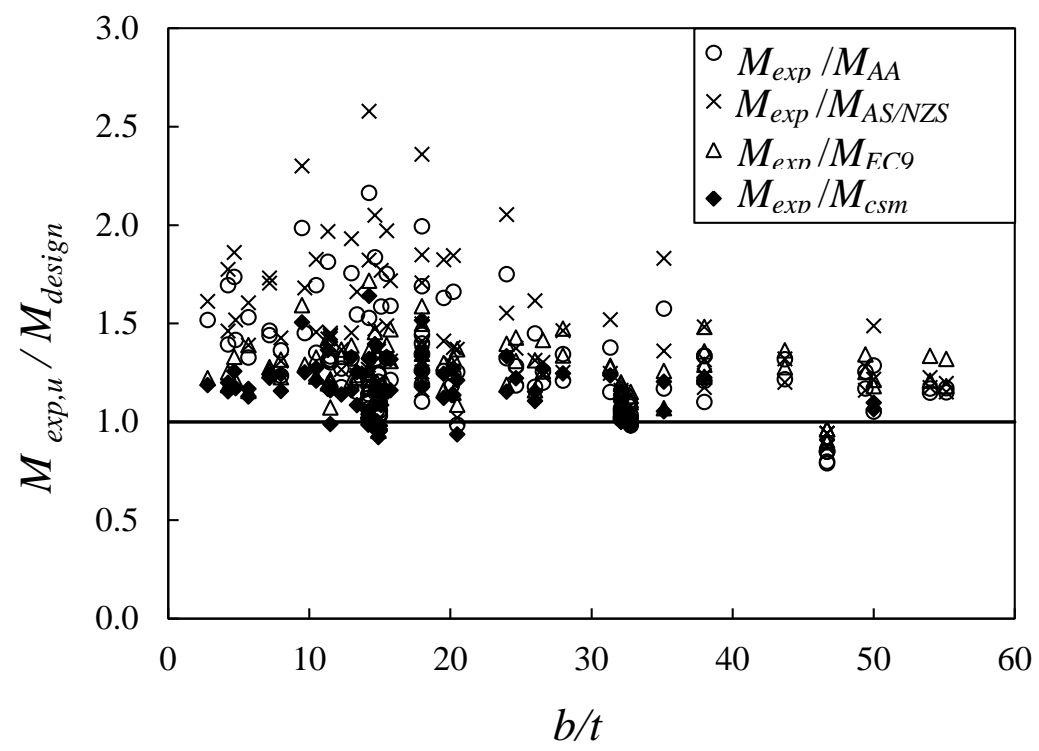

Figure 14. Comparison of three-point bending experimental results and numerical with design strengths

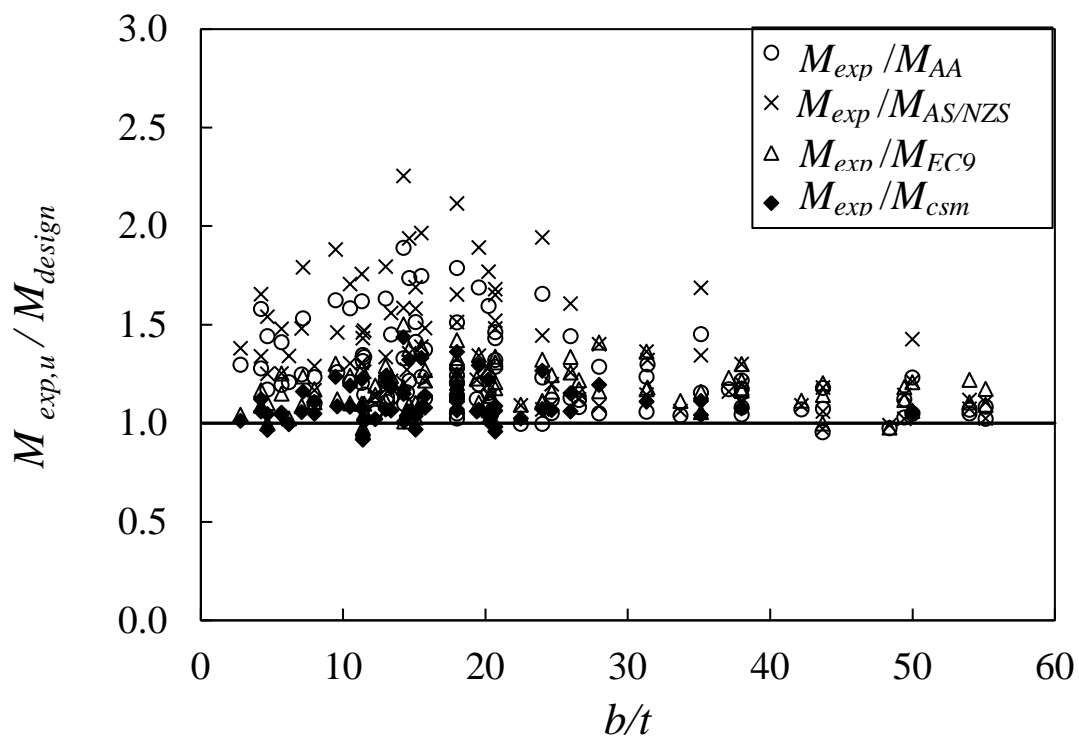

Figure 15. Comparison of four-point bending experimental results and numerical with design strengths 


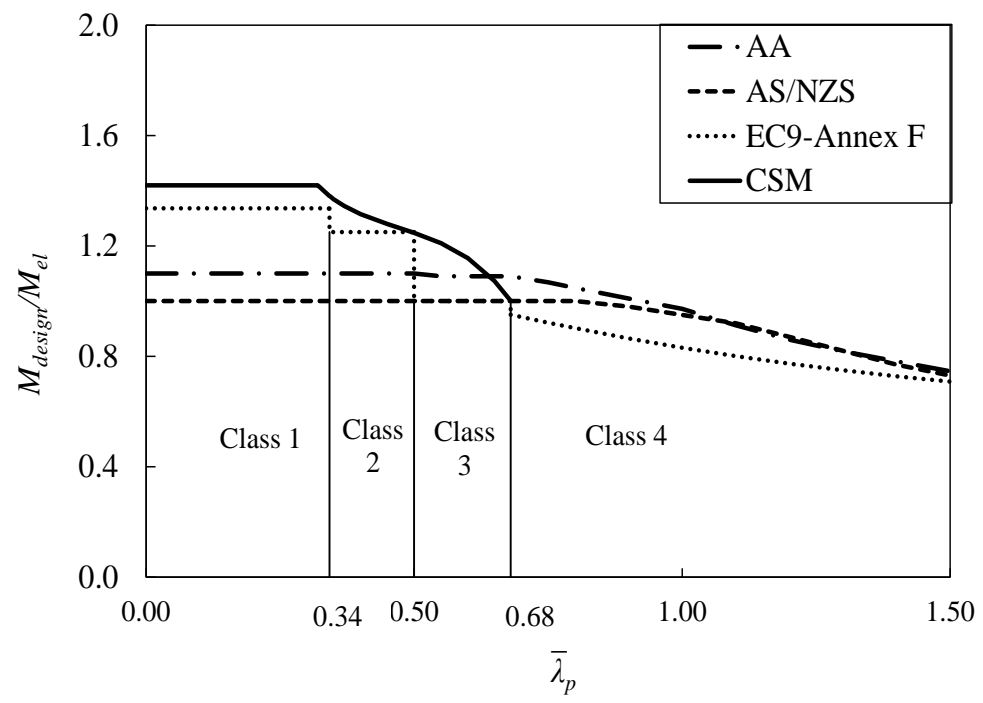

Figure 16. Curves indicating design capacities from different design approaches aluminium alloy elements in bending

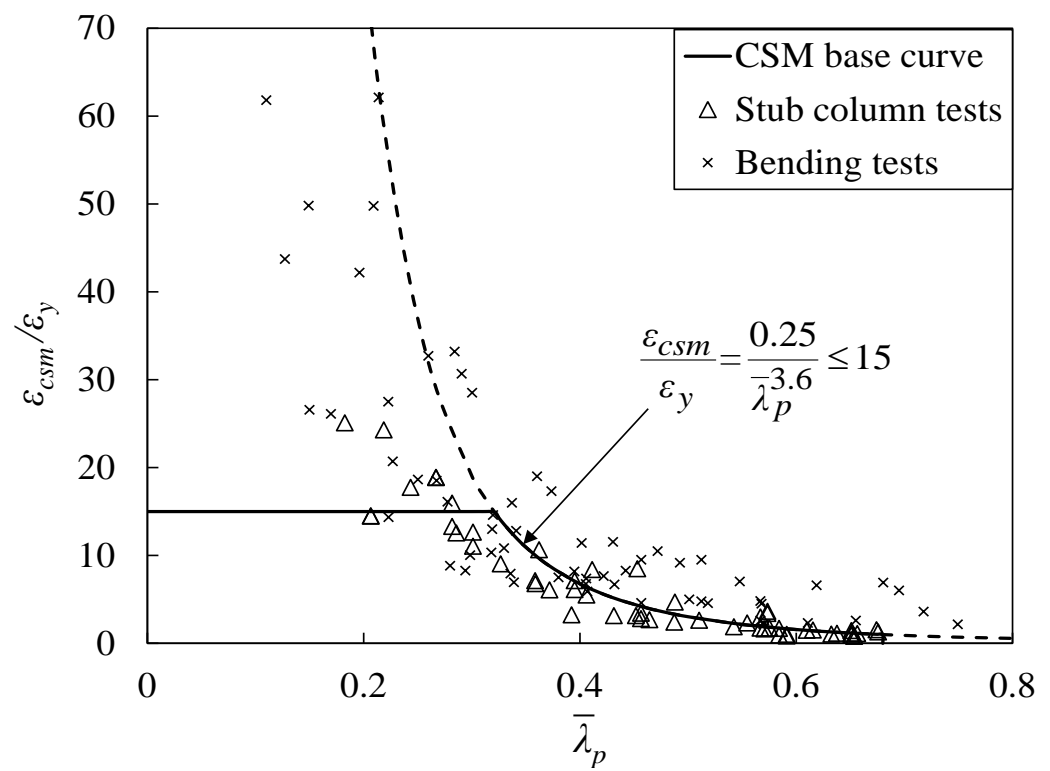

Figure 17. Comparison between four-point bending experimental and numerical results and the CSM design base curve 


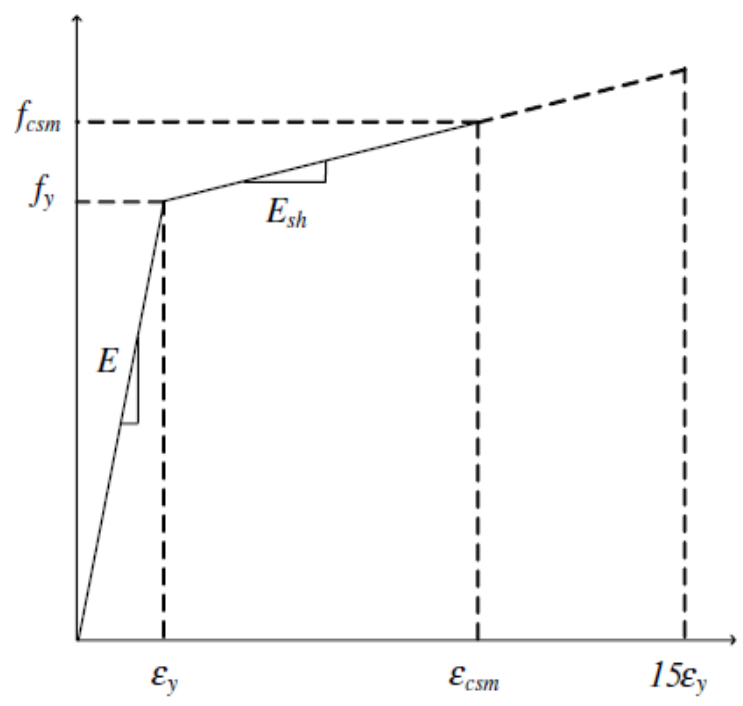

Figure 18. CSM bi-linear material model for aluminium alloys 